\title{
Migración china en Tocopilla. Heterogeneidad relacional y transformaciones internas (Chile, 1884-1960) ${ }^{1}$
}

\section{Chinese migration in Tocopilla. Relational heterogeneity and internal transformations (Chile, 1884-1960)}

Fecha recepción: octubre 2020 / fecha aceptación: enero 2021

Damir Galaz-Mandakovic ${ }^{2}$ y Jorge Moraga R. ${ }^{3}$

DOI: https://doi.org/10.51188/rrts.num24.467

\begin{abstract}
Resumen
A partir de hallazgos documentales rastreados en el Archivo Provincial de la ciudad de Tocopilla y en el archivo del Ministerio de Bienes Nacionales, entregamos antecedentes y algunas propuestas para explicar la heterogeneidad y transformaciones internas de la migración china en esta ciudad. Si bien dicho colectivo fue objeto de discriminación y racismo, en especial relacionado con su presencia y actividades en espacios marginales y delictuales de la ciudad, los documentos analizados dan cuenta de la existencia de estrechas redes con diferentes segmentos sociales, que derivaron en la elitización de un fragmento muy visible del mundo chino. Este proceso de elitización estuvo concentrado en un grupo de "grandes hombres" -en especial a partir de los años 30- y vio su consolidación en las décadas siguientes, como lo demuestra la relevante participación de esta comunidad en la transmisión y compraventa inmobiliaria hacia fines de la primera mitad del siglo $X X$
\end{abstract}

Palabras clave: Migración china; Tocopilla-Chile; huaqiao; cantoneses.

\footnotetext{
1 Este artículo es resultado de los proyectos Fondecyt № 11160648 y № 11180932.

2 Doctor en Historia y en Antropología. Universidad Católica del Norte. Dirección postal: Avda. Angamos 0610, Antofagasta, Chile. Email: damirgalaz@gmail.com

3 Doctor en Antropología. Universidad Central de Chile, Vicerrectoría Académica-Facultad de Derecho y Humanidades. Dirección postal: Lord Cochrane 417, Santiago, Chile. Email: simpulum@yahoo.com
} 


\begin{abstract}
Based on documentary findings traced in the Provincial Archive of the city of Tocopilla and in the archive of the Ministry of National Assets, we provide antecedents and some explanatory proposals regarding the heterogeneity and internal transformations of Chinese migration in this city. Although this group was the object of discrimination and racism, especially related to its presence and activities in marginal and criminal spaces of the city, the documents analyzed show the existence of close networks with different social segments, which led to the elitization of a highly visible piece of the Chinese world. This process of elitization was concentrated in a group of "big men" -especially from the 1930 s on- and saw its consolidation in the following decades, as evidenced by the relevant participation of this community in the transmission and sale of real estate towards the end. from the first half of the 20th century.
\end{abstract}

Keywords: Chinese migration; Tocopilla-Chile; huaqiao; Cantonese.

\title{
Introducción
}

En noviembre 1906, un encrespado senador del Partido Conservador llamado Ramón Subercaseaux Vicuña, conocido por sus pinturas y misiones diplomáticas en Europa, emitió duros comentarios contra los migrantes chinos en Chile:

Si esta migración asiática viniera en estos momentos para trabajar en las próximas cosechas, i regresara en seguida a su país o se marchara a otra parte, bienvenida fuera. Pero se sabe que esta jente se establece a firme en el país a donde llega, forma en él casa aparte i conserva sus costumbres i vicios, rechazados éstos por la moral i por el sentimiento unánime de todas las ciudades civilizadas ${ }^{4}$.

El hostil senador emitió estos comentarios en el marco de la discusión de un proyecto de ley que autorizaba al Presidente de la República a invertir algunos recursos para fomentar la llamada inmigración libre e industrial. Ante estas mociones, el citado parlamentario concluyó su larga intervención indicando: "Mi único propósito era oponerme a que se hiciera atmósfera favorable a la introducción en Chile de inmigrantes asiáticos, que yo considero la más perniciosa de las inmigraciones"5.

Ciertamente, en el universo simbólico de aquel parlamentario, la única migración posible y aceptable era la europea. El senador Luis Devoto Arrizaga, del Partido Liberal Democrático, se sumó a los dichos de su colega, señalando: "Creo que esa inmigración, no solo de chinos, que es absolutamente inadmisible, sino

4 Archivo Biblioteca Congreso Nacional de Chile, Cámara del Senado, sesión 13ạ extraordinaria en 15 de noviembre de 1906, p.351.

5 Archivo Biblioteca Congreso Nacional de Chile, Cámara del Senado, sesión 13ạ extraordinaria en 15 de noviembre de 1906, p.352. 
también de japoneses, que tienen muchos puntos de contacto con aquellos, sería muy perjudicial para el país".

Estas discursividades elitistas no eran aisladas ni desarticuladas entre la sociedad y la propia institucionalidad nacional, todas ellas daban muestra de un recelo y de una resistencia densa en un cuadro de desprecio racializado al otro. Pero no solo los políticos, en el marco del darwinismo social que devino en sinofobia, fueron los únicos en expresar una adversidad. El diario El Industrial de Antofagasta informaba en octubre de 1906 que la Sociedad Asiática de Beneficencia había realizado una declaración protestando contra la campaña emprendida por el diario El Mercurio "desfavorable a la raza amarilla", añadiendo que los desembarcados en lquique y en otras ciudades del norte eran "casi todos comerciantes que viajaban por su cuenta", distinguiendo en ello que no eran "inmigrantes, porque no venían contratados"8.

No obstante, allende de estas consideraciones de desprecio y hostilidad, curiosamente, meses antes, una activa y entusiasta colonia china participaba en Antofagasta en la bienvenida que se brindaba al presidente electo de Chile, Pedro Montt, en agosto de 1906. El Diario El Industrial notició:

La colonia china por su parte, enviaron un saludo sobre papiro con grandes caracteres negros cuya traducción dice asi: Sim Lim Guerra, en nombre de la Colonia China de Antofagasta, tiene el honor de saludar al futuro Presidente de Chile, señor Pedro Montt, por su feliz arribo a este puerto?.

Más allá del mero hecho anecdotario, este último dato nos expide a una problematización: ¿Quiénes eran los chinos discriminados y quiénes eran los que participaban sin mayor problema en la sociedad chilena y en los diversos protocolos políticos? ¿Quiénes eran los chinos considerados en el recibimiento de un presidente de la república? ¿Cómo conllevaban en su vida cotidiana aquellos chinos las imágenes de desprecios difundidas por diarios y políticos? ¿Qué tipos de chinos integraban la Sociedad Asiática de Beneficencia?

Las investigaciones más canónicas han tendido a homogeneizar y folclorizar a las comunidades chinas fuera de su país, invisibilizando su diversidad interna. Por nombrar algún clásico, el mismo Crissman a fines de la década de 1960 propuso un modelo que distinguía organizaciones chinas basadas en identidades

6 Archivo Biblioteca Congreso Nacional de Chile, Cámara del Senado, sesión 13ạ extraordinaria en 15 de noviembre de 1906, p.352.

7 El Industrial (Antofagasta), 26 de octubre de 1906.

8 El Industrial (Antofagasta), 26 de octubre de 1906. Esta diferencia la hacían para distinguirse de los antiguos coolies, la llamada "Migración por Contrato Laboral" en China.

9 El Industrial (Antofagasta), 16 de agosto de 1906. 
territoriales y de lengua ${ }^{10}$, con una considerable clausura en sí mismas. Algunos incluso observan algunas de estas características a nivel mundial (Nieto, 2007; Wang, 2011). Sin entrar en tal discusión, y concediendo que lengua y territorio algún peso mantienen en las comunidades migrantes, quisiéramos abrir la pregunta en torno a lo ocurrido en Chile, donde esos mundos chinos no fueron homogéneos, sino internamente muy diversos en los momentos temporales que analizamos en este texto. Quizás tan diversos como los espacios sociales y alteridades, no solo de clase, sino étnicas y regionales, presentes en la sociedad chilena por la cual ellos derivaron. Una diversidad china en Chile que en los comienzos del siglo XX en parte se explica por su origen territorial y de su lengua común, pero más por sus conflictos y alianzas con los nativos chilenos. Es lo que pretendemos destacar. Con disposiciones sociales presentes en dichos nativos, los chilenos, que tampoco se explican solo por la construcción de un imaginario racista que habría obligado a la exclusión de ese "otro" inasimilable. Pues, al parecer, ese otro chino no fue tan inasimilable. Al contrario. Los textos y discusiones que serán expuestos, si bien no están exentos de juicios racistas que amenizan la lectura, dan cuenta de un estrecho contacto e interacción entre segmentos sociales chinos y chilenos. Entonces, primero y gruesamente ¿Qué estructuras culturales explican esos ensambles o fisuras con la sociedad de llegada? Y luego, volviendo a la diferencia interna: ¿qué sujetos sociales chinos son los que buscaron reconocimiento ante el Presidente de la República de Chile durante una visita a Tocopilla en 1929, y quiénes de ellos lo hicieron en espacios sociales que, al menos la discursividad nativa oficial, marcó como delictuales?

La presente investigación histórica está basada en la revisión de un extenso archivo documental perteneciente al Archivo Provincial de la ciudad de Tocopilla (Región de Antofagasta, Chile) que contiene documentos de la propia Gobernación Departamental y también documentos de la gestión municipal desde los finales del siglo XIX". Dichos hallazgos documentales nos dan algunas luces respecto a los procesos heterogéneos de la migración china en Tocopilla, en cuanto a la percepción local de la migración, a los entramados de discriminación, también la narración de actos considerados como delictuales, la propia marginalidad, pero también al devenir del establecimiento de redes, diversos modos de relaciones sociales, a las agencias de institucionalización y también a la elitización y distinción que en general fue caracterizando a este colectivo migrante de cantoneses. Estos reportes fragmentarios de la vida cotidiana en este período, que nos permiten identificar y visibilizar a sujetos diversos, se complementan con datos obtenidos en diversas fuentes hemerográficas, especialmente diarios locales y regionales. Del mismo modo, podemos identificar, cuantificar y caracterizar a través de

10 En China se suelen distinguir tres grandes bloques lingüísticos: el mandarín o Puntunhua (lengua del norte), actual lengua franca impulsada por Pekín; el Wu, en la zona de Shanghai y el centro costero; y el cantonés, cuyas variantes se escuchaban a comienzos del siglo XX en Chile. Los límites de la lengua y las filiaciones parentales derivadas de sus lugares de origen han sido consideradas tradicionalmente como la principal marca de diferenciación interna entre los chinos de ultramar (Crissman 1960). Estudios más actuales demuestran que son otros factores los que definen el comportamiento de estas poblaciones (Vgr., Greenhalgh, 1994 y 2010).

11 Si bien logramos entrever que el "archivo" reproduce un dispositivo de poder, quisiéramos objetivar en parte nuestra posición, explicitando que indagamos en palabras escritas en español y desde archivos chilenos. 
datos obtenidos en los archivos del Ministerio de Bienes Nacionales, situados en Tocopilla, sobre los procesos relativos a las transacciones de propiedad privada que desplegó la colectividad china en Tocopilla. En ellos se demuestra la relevante participación de la comunidad china en la transmisión y compraventa inmobiliaria, constatando la complejidad de las relaciones entre chinos y nativos en la primera mitad del siglo $X X$.

Este artículo propone que la migración china, amén de su participación marginal en una sociedad del desierto costero de Atacama recientemente incorporado a Chile, además de una serie de imágenes aciagas que se construyeron sobre ella, -que entre otras cosas significó una sinofobia densa- fue estableciendo las agencias de articulación que devinieron en una elitización local y una considerable distinción social, siendo los indicadores de ello las actividades comerciales, la notoriedad social y la gestión inmobiliaria. No obstante, este devenir no sería de una homogeneidad integral, como suele proponer la lectura nativa, porque a pesar de estos rasgos de elitización, siguieron existiendo chinos situados en la marginalidad, surgiendo así un proceso antropológicamente heteróclito y singular. En ese sentido, podemos preguntarnos si acaso hubo sinofobia en los finales del siglo XIX y principios del siglo $X X$, o realmente lo que se evidenció socialmente fue una aporofobia que estigmatizó y mancilló a algunos migrantes chinos en razón de su rezago, pobreza y marginalidad.

\section{Migración china y marginalidad tocopillana}

En noviembre de 1884, el puerto salitrero de Tocopilla atestiguaba algunos hechos sombríos ocurridos en un lugar mencionado como Café Chino ${ }^{12}$. El diario El Industrial comentaba en duros términos: "En un Café de Chino, raza que por desgracia abunda en este puerto (...) se ha perpetrado un horroroso crimen en una pobre mujer llamada Lorenza Barrios"13.

Los detalles entregados por el matutino antofagastino indican que la mujer había llegado a dicho café en donde se hallaban varios chinos, uno de ellos era su marido, sin embargo, sin mayor explicación, la mujer fue encerrada en uno de los cuartos del inmueble,

acompañada de un niñito de uno a dos años, donde era visitada por los distintos chinos que en aquel café se encontraban. Esto había sido notado por unos vecinos del lado, i temiendo que a más de las visitas se cometiera algún crimen, se presentaron al señor gobernador esponiéndoles sus temores ${ }^{14}$.

Ejecutado el denuncio en la gobernación por parte de los vecinos, se impartieron las órdenes para un allanamiento policial a dicho Café Chino. El diario relata:

12 El semanario La Cachimba (Antofagasta) en su edición del 31 de mayo de 1930 indica que un café chino era una "casa de citas"; es decir, un lugar donde se ejercía la prostitución clandestina.

13 El Industrial (Antofagasta) 29 de noviembre de 1884.

14 El Industrial (Antofagasta) 29 de noviembre de 1884. 
Al presentarse ésta, los chinos se quedaron sin saber qué hacer, protestando que nada habían hecho; pero la policía sin hacer caso de esto $i$ viendo la confusión que se pintaba en todos ellos, hizo abrir una puerta que daba a un cuarto i lo primero que se presentó a su vista, fué la pobre mujer, joven como de 18 años, que yacía exánime en su sucio lecho ${ }^{15}$.

De inmediato, el cuerpo fue levantado y la policía esgrimió una hipótesis: "Se presume que fué envenenada con opio, poniéndole en la bebida"16.

Fue entonces que los nueve chinos fueron rápidamente detenidos y "fueron conducidos al cuartel de policía (...) adonde han permanecido bien custodiados e incomunicados"17. Los apresados fueron enviados a Antofagasta en un vapor llamado Lautaro, ciudad donde fueron puestos a disposición del Juzgado local, lugar en donde fueron condenados.

Sucesos como estos, auxiliados por la difusión y comentarios perniciosos de la prensa, fueron construyendo una imagen centrada en la negatividad hacia los migrantes chinos en Tocopilla, quienes, desde los finales del siglo XIX, fueron habitando las periferias de la urbe, particularmente en las zonas cercanas a los cerros, las que también eran afamadas por ser espacios de sociabilidad con excesos de goce: "chinganas (donde) corría el licor y se cometían muchos delitos. A estos locales el bajo pueblo acudía armado de revólveres, cuchillos y manoplas", nos comenta el cronista local Juan Collao (2001 [1970], p.100).

Una vez superada la epidemia de la Fiebre amarilla en Tocopilla en 1912, surgieron una serie de disposiciones referidas a la gestión de la basura y al control que debiese ejercer la policía en los barrios suburbanos. Uno de estos controles llevó a la policía a denunciar ante el gobernador sobre "la oscuridad de los barrios periféricos", por causa de no contar con alumbrado público, lo cual impedía la realización de fiscalizaciones en esos barrios, en especial: "La parte de la calle de Colón hacia el norte no se enciende ninguna luz quedando esa parte completamente oscura, siendo que ahi existen todos los salones de prostibulos, casas de comercio i mataderos de chinos"18. De esa manera, se visibilizaba que los barrios marginales de la ciudad contaban con migrantes chinos que trabajan el "negocio de las carnes muertas" (Collao, 2001 [1970, p. 118) en barrios donde por efecto de la oscuridad pueden "suceder en no lejano día algún asalto quedando impune, como así también actividades de contrabando no pudiendo evitarlo la policía, debido esclusivamente al pésimo servicio del alumbrado que hoi existe en toda la población"19, señala un documento policial de agosto de 1912.

\footnotetext{
15 El Industrial (Antofagasta) 29 de noviembre de 1884.

16 El Industrial (Antofagasta) 29 de noviembre de 1884.

17 El Industrial (Antofagasta) 29 de noviembre de 1884.
}

18 Archivo Provincial de Tocopilla, Oficio № 12, Al Sr. Gobernador, remite: Juan Carlos Bischofshofen, prefectura de policía, 17 de agosto de 1912.

19 Archivo Provincial de Tocopilla, Oficio № 12, Al Sr. Gobernador, remite: Juan Carlos Bischofshofen, prefectura de policía, 17 de agosto de 1912. 
Sobre la mención al negocio de las "carnes muertas", cabe indicar que este fue desarrollado por varios chinos, no solo en la calle recién mencionada, sino también en los sectores de la playa al margen norte de los límites urbanos. En el decir del investigador Juan Collao, desde el segundo lustro de la década de 1880 algunos chinos se instalaron con tolderías y "rucos" en la costa, "alimentándose por caridad, de la peor carne que obtenían del matadero municipal, que por entonces se encontraba en las playas, a la altura de la calle Washington, y restos de comida que obtenían en la población o que encontraban en los tarros de basura" (Collao, 2001 [1970], p.293).

En esas circunstancias, los chinos pudieron conseguir diversas menudencias que empezaron a "vender en los barrios más humildes, llegando después a tener sus propios camales donde sacrificaban cerdos y corderos, lugares que se caracterizaron por la falta absoluta de higiene, malos olores y abundantes mosqueríos" (Collao, 2001 [1970], p.293). Añadiendo que esta actividad se desarrolló "entre el barranco y la playa20 (...) sin observar las más mínimas condiciones de higiene y reglamentos sanitarios" (Collao, 2001 [1970], p.176). Todas estas imágenes de supuesta insalubridad, iban acompañadas por una prensa racista y prejuiciosa que difundía contenidos durísimos, tal como El Industrial, que en su edición del 6 de enero de 1906 titulaba una pregunta: “¿Por qué comen ratones los chinos?”21.

Se constata entonces el ensamble de un grupo de chinos en espacios sociales por los que transitan nativos chilenos de capas populares de la población local. Espacios en la marginalidad urbana, donde se ejerce la prostitución y se consume opio ${ }^{22}$. No hay estudios sobre la propiedad de dichos establecimientos, pero sí queda clara la presencia de vínculos que permiten la existencia de clientes consumidores y también de mujeres nativas que ejercen la prostitución en locales cuya propiedad es de chinos. En paralelo, se aprecia la existencia de espacios donde se negocian y venden otras carnes, las de animales muertos, generando un mercado de interiores de animales comandado también por el mundo chino, que al parecer dialogó y marcó la cocina popular de la zona. Es interesante constatar que esos primeros carniceros que revendían interiores donados por chilenos en la primera década del siglo XX tenían instalados mataderos propios, quizás insalubres o fuera de la ley, pero de su propiedad, donde sacrificaban sus animales. Más aún, ya en la década

20 El cronista se refiere al barranco costero existente desde calle Colón y Washington hacia el norte.

21 A la pregunta "¿Por qué comen ratones los chinos?", el diario respondía: "parece que es para hacer crecer el cabello (...) las ratas producen en el cabello humano el mismo efecto que las zanahorias en los caballos. Todo aficionado a los caballos sabe que aquel es el mejor medio de dar a este animal un pelaje brillante y suave". La delirante nota también afirmaba que con dicha digestión de roedores "se detiene la caída del pelo. Y al revés, el cabello toma mayor fuerza y se hacen brillantes y suaves como la seda". La irracionalidad de estos comentarios concluía con una ironía: "Ya lo saben los calvos y los que van para tales. Solo falta que hagan la prueba" (El Industrial, 6 de enero de 1906).

22 Salvo excepciones (Henríquez 2004; Salazar 1985; Stuven y Fermandois 2011), no se ha profundizado en el trabajo sexual ni en las condiciones de vida en los sitios donde se la practicaba en el norte salitrero de Chile, incluyendo por cierto los fumaderos de opio controlados por chinos, pese al evidente vínculo entre capitalismo, minería y prostitución (Kalazich 2018). 
siguiente, a mediados de los años 20 , estos negocios ya representan una abierta competencia en su rubro, lo que causaba resquemores en el comercio local ${ }^{23}$.

Hacia mayo de 1923, una carta firmada por el alcalde de Tocopilla, Eduardo Mascayano, acusaba con el Gobernador del Departamento de Tocopilla a algunos ciudadanos chinos por participar en actividades comerciales de "modo des/eal", solicitando a la autoridad que interviniera; en ese cuadro:

La I. Municipalidad en sesión de fecha 11 del presente, acordó pedir a Ud. su valioso concurso a fin de que se cree una comisión para estudiar los reclamos de algunos comerciantes de carnes $i$ comidas calientes sobre el comercio desleal que ejercen algunos ciudadanos chinos en Tocopilla ${ }^{24}$.

Dichas acusaciones estaban remitidas a que los chinos desarrollaban, aparentemente, actividades sin los permisos sanitarios correspondientes y "de vender a precios que perjudican al comercio establecido i de negociar con barcos pacotilleros en el muelle de pasajeros burlando a los controles policiales"25. Es por ello que la acusación y reclamo contra los chinos era, según las consideraciones de la sesión municipal, "un problema público primordial", al punto de decir que: "esta alcaldía vería con agrado tuviera a bien aceptar esta comisión"26.

Estos problemas tuvieron una larga data. Porque, incluso, en 1931 la municipalidad volvió a expresar una hostilidad con los chinos, pidiendo sin ambages restricciones a este colectivo. Al menos así lo explicitó el alcalde Luis Cárcamo en un oficio que envió al intendente de Antofagasta en marzo de 1931 en el cual denunciaba una serie de hipotéticos vicios: "Sr. Intendente (...) solicito a Ud. tener mayores controles sobre la inmigración asiática al Departamento, especialmente en Tocopilla, puerto donde día a día llegan grandes grupos de chinos" 27.

Esta acusación evidenciaba un fuerte sustrato racista al indicar que la propia migración china era un "peligro ante la raza (chilena), pueden degenerarla a través

23 Según constata Bao Rong: "A diferencia de los chinos que llegaron a Chile en el siglo XIX, los chinos que arribaron después de 1900 ya no lo hicieron en calidad de culi, sino principalmente gracias a las invitaciones de familiares y amigos que ya residian en el país. Las ocupaciones más comunes de esta nueva generación se mantenían en las salitreras, a lo que se agregó la tenencia de negocios de abarrotes y carnicerías. Sin ir más lejos, en el año 1913, en aquellos pueblos cercanos a las salitreras, el número de negocios de abarrotes aumentó a 92. También aparecieron seis carnicerías, dos cafés y un hotel. Todos locales a cargo de chinos" (Bao 2013). Datos similares sobre la época se encuentran en Chou (2004). En 1917, el diario La Nación comentaba: "No tiene para nosotros ventaja alguna la infiltración de inmigrantes chinos en nuestra población. Es cierto que se trata en muchos casos de hombres sobrios y humildes que abaratan grandemente el costo de la mano de obra (...) vienen a estremar el problema social de la oferta y la demanda del trabajo, no es deseable" (15 de enero de 1917).

24 Archivo Provincial de Tocopilla, Oficio №34, Al Sr. Gobernador, remite Alcalde E. Mascayano, 27 de mayo de 1923.

25 Archivo Provincial de Tocopilla, Oficio №34, Al Sr. Gobernador, remite Alcalde E. Mascayano, 27 de mayo de 1923.

26 Archivo Provincial de Tocopilla, Oficio №34, Al Sr. Gobernador, remite Alcalde E. Mascayano, 27 de mayo de 1923.

27 Archivo Provincial de Tocopilla, Oficio №23, A/ Sr. Intendente de Antofagasta, petición de restricciones a la inmigración china, firma alcalde L. Cárcamo, 19 de marzo de 1931. 
de la insalubridad en la venta de carne, además de su afición por el juego". Señalando, además, que día a día llegaban a la municipalidad "quejas de comerciantes y vecinos de buen vivir. Es de esperar medidas correctivas antes estos foráneos que perjudican a nuestra población" ${ }^{28}$.

A esas escenas, podemos añadir los datos que nos remiten a ciertos conflictos que establecieron chinos con otros migrantes internacionales. Hacia octubre de 1921, se presentó la situación de unos chinos que fueron apresados por riñas e intento de incendio en un local comercial perteneciente a un yugoslavo. La policía comunicó:

...quisiera informar que la situación de los tres ciudadanos chinos involucrados en la pelea del 29 de setiembre en las afueras del local comercial del Sr. Bakulic, se encuentran detenidos, ya que según el señor Bakulic los ciudadanos chinos querían incendiar el local comercia/29.

El documento policial indica que los detenidos rechazaban todas las imputaciones:

señalan que solamente habían ido a buscar las mercaderías que habían sido compradas i comprometidas por el Sr. Bakulic que, aseguraron, las obtiene a través de vapores pacotilleros. Acusando al mismo tiempo de contrabandista al comerciante ${ }^{30}$.

Cabe indicar que el yugoslavo Nikolas Bakulič era un comprador al por mayor de mercaderías en el puerto, las que luego revendía a comerciantes minoritarios, entre ellos los chinos, pero aquel yugoslavo allegado desde la isla de Brač, era famoso por los contrabandos.

Las actividades comerciales de los chinos también generarían algunas pulsiones securitarias, para así poder comerciar y desplazarse dentro de la ciudad con tranquilidad, para ello fue prioritario el uso de armas ante los excesos de asaltos y quitadas de mercaderías. Tenemos el caso de Federico Loo Ku, quien el 7 de febrero de 1924 elevó una solicitud del gobernador:

Federico Loo Ku, de nacionalidad china, comerciante de carnes $i$ radicado desde varios años en esta ciudad, á Ud. con todo respeto digo: Que, en resguardo de mi persona i por tener que traficar á veces tarde de la noche por barrios apartados de la Colonia (Villa Esmeralda) tal vez con grave peligro de ser asaltado por jente de malos antecedentes que merodea por partes más solas de la población ${ }^{31}$.

28 Archivo Provincial de Tocopilla, Oficio №23, A/ Sr. Intendente de Antofagasta, petición de restricciones a la inmigración china, firma Alcalde L. Cárcamo, 19 de marzo de 1931.

29 Archivo Provincial de Tocopilla, Oficio s/n, Al Sr. Gobernador Departamental, Remite: Comisario Jorge Bonilla, 1 de octubre de 1921.

30 Archivo Provincial de Tocopilla, Oficio s/n, Al Sr. Gobernador Departamental, Remite: Comisario Jorge Bonilla, 1 de octubre de 1921.

31 Archivo Provincial de Tocopilla, carta s/n A/ Sr. Gobernador: solicitud para uso de arma, 7 de febrero de 1924. 
De esta forma el ciudadano chino daba cuenta de una escena delincuencial y de peligrosidad en los sectores limítrofes, por tal razón, el uso de un arma era primordial:

con todo respeto permítame solicitar el permiso para cargar revólver por el término del presente año, sometiéndome á dar cumplimiento en todas sus partes á las disposiciones dictaminadas por la Gobernación de su digno cargo 32

El sector que Federico Loo Ku denunciaba como "apartados de la Colonia (Villa Esmeralda)", se refería a un barrio que colindaba con la termoeléctrica perteneciente a The Chile Exploration Company de la familia Guggenheim, usina encargada de energizar a la gran mina de Chuquicamata. Dicho barrio era el espacio intermedio entre un Company town de la misma termoeléctrica y la ciudad tradicional, es por ello que los estadounidenses, en el marco del ejercicio del control social que ejercían, comenzaron a presionar a las autoridades para generar la caducidad de patentes y así ejercer el cierre de cantinas y restaurantes, o cualquier otro espacio que promoviera el consumo de alcohol. Quizás, era a ellos a los que el comerciante chino temía y se sentía amenazado. En ese contexto, surgieron verdaderas campañas de delación y la compañía estadounidense denunció a otro ciudadano chino residente en el mismo barrio colindante, sobre el cual "tenemos serias sospechas del manejo de sustancias ilícitas"33.

Diez días después, la policía informaba al mismo Gobernador que el martes 24 de abril de 1927, a las 12 del día, que, junto al Médico Sanitario Dr. Vivanco, el Inspector Sanitario Sr. Jénaro Castro, el Guardián 1ำ Luis Donoso y el Guardián 3ํA Agundio Sepúlveda, sorprendieron al ciudadano chino Higinio Hauyon Kong, domiciliado en Calle Riquelme №721 (Villa Esmeralda), con la instalación de un fumadero de opio ${ }^{34}$, quien estaba en ese departamento al momento de la inspección:

donde se encontraron varios frascos y tarritos con ese narcótico, como asimismo la cachimba de fumar y existencia en píldoras de esa misma droga, las que fueron recojidas por el Médico Sanitario para entregarlas al Juzgado a las órdenes de quien pasó el detenido Hauyon (...) Los sorprendidos en tráfico de alcaloides, se les debe aplicar la Ley de

32 Archivo Provincial de Tocopilla, carta s/n A/ Sr. Gobernador: solicitud para uso de arma, 7 de febrero de 1924.

33 Archivo Gobernación Provincial de Tocopilla, Oficio № 16 Comisaría de Tocopilla al Sr. Gobernador: dá cuenta de fumadero de opio y pide aplicación de Ley de Residencia”, 26 de abril de 1927.

34 El consumo de opio era una realidad que acontecía en las principales ciudades del norte de Chile. En diciembre de 1921, el diario antofagastino El Abecé, entregaba algunos detalles (sin excluir los duros juicios de valor) sobre el impacto de la difusión de fumaderos en calles céntricas: "El opiómano, que se caracteriza por la excesiva dilatación de las pupilas y por un aspecto de decaimiento general es un verdadero anormal que por satisfacer la necesidad imperiosa de fumar la ansiada droga no trepida en cometer cualquier acto delictuoso (...) el opiómano va perdiendo más y más el control sobre sus facultades físicas e intelectuales hasta llegar a convertirse en un miserable harapo". Según el mismo diario, la difusión de fumaderos de opio por acción de chinos existía porque "no son molestados por las autoridades, a los cuales concurren gran número de habitués" (El Abecé, 7 de diciembre de 1921). 
Residencia ${ }^{35}$, lo que pongo en conocimiento de Ud. para los fines del caso. Ramón Reyes Sub-Comisario Jefe ${ }^{36}$.

Estas delaciones empresariales que sobrevienen en clausuras de tabernas y restaurantes, y los respectivos allanamientos, fue una gestión ante agencias que poseían la supuesta potencia de afectar el disciplinamiento laboral y barrial, eran la expresión de una campaña empresarial y particular que, de una u otra manera, era extensiva a quienes no tenían vinculación laboral con la compañía, entre ellos, en este caso, un ciudadano chino.

En referencia a la marginalidad de aquellos emplazamientos, es destacable que durante la gira presidencial de Carlos Ibáñez del Campo, en 1929, en su ingreso a Tocopilla la comitiva debió pasar por la miseria del barrio norte de dicha ciudad, conocido como "La Manchuria", un conjunto de tolderíos hechos con sacos, cartones, latas y maderas, insalubre por falta de agua y alcantarillas (La Prensa, 7 de agosto 1929). En el lugar se asentaron diversos grupos populares, incluyendo parte de la colonia china, de cuya presencia derivó el nombre del sector en su conjunto.

Evidentemente, las miradas que acontecen sobre el colectivo migrante son heterogéneas, porque si bien algunos eran denunciados y apresados, otros eran autorizados para portar armas en una escena de conflictos e inseguridades urbanas. Hacia el año 1929, el propio gobernador departamental Juan Bautista Fuenzalida autorizó a cinco ciudadanos chinos para el porte de revolver, mas, no indica los motivos específicos:

Al Prefecto de policía: El infrascrito autoriza a los siguientes ciudadanos chinos con residencia en Tocopilla a portar revolver como medida de protección en sus tránsitos por zonas inseguras de nuestro litoral: 1) Juan Kong Loo, 2) Heun Yep Ku 3) Iwan Chong Joo 4) Juan Chang y 5) Ypung $L y^{37}$.

Esta autorización estaba basada en la buena conducta de los mencionados, que "acreditaron buenos antecedentes en esta gobernación"38. El documento constata entonces la diversidad interna del mundo chino y los privilegios en el trato de parte de la autoridad nativa, más evidente aún ante la marcada restricción para la entrega de visas a ciudadanos de esa nacionalidad que se apreció al menos desde 1912, cuando el Estado las acotó a un máximo de 20 mensuales. Luego, en

35 La Ley de Residencia, promulgada el 12 de diciembre de 1918, fue catalogada como Ley № 3.446. Permitía la expulsión de los extranjeros residentes en Chile que hubiesen cometido algún delito común establecido por el Código Penal. Fue recurrentemente usada para expulsar a sindicalistas y anarquistas. Fue derogada el 19 de julio de 1975. (Ley N³.446, 1918).

36 Archivo Gobernación Provincial de Tocopilla, Oficio № 16 Comisaría de Tocopilla al Sr. Gobernador: dá cuenta de fumadero de opio y pide aplicación de Ley de Residencia”, 26 de abril de 1927.

37 Archivo Provincial de Tocopilla, Oficio № 99, Al Prefecto de Policía de Tocopilla, remite Gobernador Fuenzalida, autorización uso de armas, 9 de marzo de 1929.

38 Archivo Provincial de Tocopilla, Oficio № 99, Al Prefecto de Policía de Tocopilla, remite Gobernador Fuenzalida, autorización uso de armas, 9 de marzo de 1929. 
1914 incluyó la presentación de certificados de buena salud ${ }^{39}$ y a partir de 1915 el cobro de 10 pesos por tramitarla (en un contexto en el que no se cobraba a ninguna otra nacionalidad), a lo cual desde 1921 se sumó la exigencia de una garantía de 185 dólares, la cual subió a US 350 en 1930, cuando sólo se registró el ingreso de 72 chinos con visa a Chile (Bao, 2013).

Quizás por lo mismo, hubo otros casos en que el deseo de armarse fue negado. En 1938, carabineros rechazó otorgar permisos a Jau Chang para portar armas, quienes argumentaron lo que sigue:

Revisados los antecedentes que registra en el Gabinete de Identificación el solicitante, se constataron varias detenciones por diferentes delitos, lo que lo hace aparecer como una persona de procedimientos poco correctos, cuya reputación deja bastante que desear, máxime si se considera que una de estas detenciones es por contrabando" 40.

El informe agregaba que el ciudadano era de un "temperamento violento e irritable, lo que está en pugna con las condiciones que debe poseer una persona que carga armas" ${ }^{41}$. Dichas características llevaron a considerar que el recurrente no poseía, además, el dominio del arma que deseaba cargar, lo que constituía un peligro, "dado que la torpeza en su manejo puede ser de fatales consecuencias" 42. Al mismo tiempo, Carabineros indicaba que no era efectivo que el señor Jau Chang tuviera que salir constantemente del radio urbano de la ciudad llevando dinero y mercaderías consigo, "pues, se trata de un comerciante establecido con un almacén de menestras" 43 . En virtud de los mencionados antecedentes, la Prefectura estimó que no debía accederse a la petición.

39 Sobre los temas sanitarios, los chinos fueron violentamente acusados de ser vectores de diversas enfermedades. El diario La Nación (Santiago) señaló: “...hay que recordar una vez más a nuestros poderes públicos que todas las enfermedades exóticas que hoy afligen a los habitantes de este país, han sido importadas exclusivamente por inmigrantes chinos, recibidos aqui sin restricción ni formalidad sanitaria de ninguna especie. Por este camino vamos a la peor de las catástrofes..." (La Nación, 15 de enero de 1917).

40 Archivo Provincial de Tocopilla, Oficio №110, Al Sr. Gobernador. Remite: J. Lafourcade Mendoza, Mayor de Carabineros, 22 de julio de 1938.

41 Archivo Provincial de Tocopilla, Oficio №110, Al Sr. Gobernador. Remite: J. Lafourcade Mendoza, Mayor de Carabineros, 22 de julio de 1938.

42 Archivo Provincial de Tocopilla, Oficio №110, Al Sr. Gobernador. Remite: J. Lafourcade Mendoza, Mayor de Carabineros, 22 de julio de 1938.

43 Archivo Provincial de Tocopilla, Oficio №110, Al Sr. Gobernador. Remite: J. Lafourcade Mendoza, Mayor de Carabineros, 22 de julio de 1938. 


\section{Formación del Centro Chung Hwa}

De modo simultáneo a estas escenas de acusaciones y críticas hacia los chinos, en el año 1928 migrantes chinos formaron el Centro Chung Hwa de Tocopilla, organización que adquirió terrenos en la principal calle de la ciudad y construyó un inmueble que se inauguró en 1933. El local comenzó a ser usado para fiestas, cenas, ceremonias, reuniones, velorios y casamientos de la propia colectividad.

La agrupación fue integrada por comerciantes que en el segundo lustro de la década de 1920 habían desarrollado algunos procesos de acumulación por efecto de sus actividades comerciales, casi todas remitidas a la venta de carnes y la creación de restaurantes. Juan Collao comentó que los chinos "rechazados en su integración (...) se vieron obligados a surgir por si solos, con grandes sacrificios y privaciones hasta lograr instalarse con sus negocios de carnicerías despachos, casas de cena y otras actividades de mayor rentabilidad y respeto"(Collao, 2001 [1970], p.293).

El 6 agosto de 1929, en la mencionada visita a Tocopilla del Presidente Carlos Ibáñez del Campo, gran parte de la ciudadanía salió a las calles a saludarlo, entre ellos la colonia china. El diario La Prensa dijo:

La colonia china levantó entre las calles Washington y Colón un hermoso arco de arquitectura asiática con la inscripción 'La colonia Chung Hwa al Protector de Tocopilla'. Además, decoraban el arco inscripciones doradas en caracteres asiáticos que significaban votos de felicidad para el mandatario ${ }^{4}$.

De esta forma, la participación de la colonia proyectaba una nueva visibilización. Sin duda que, la creación del Centro Chung Hwa y la participación en el recibimiento de un presidente, remiten a un momento clave en la consolidación de una élite interna en la comunidad china.

Otras acciones de Chung Hwa fue hacer resistencia y expresar las molestias contra algunas agrupaciones de teatro que ridiculizaban a la colectividad. El presidente de Chung Hwa en 1932, Juan Chang, envió una carta a la gobernación, liderada por Arturo Peralta, alzando un reclamo contra el grupo de teatro y Conjunto de Variedades Los Criollos: "Como presidente del Centro Chung Hwa de Tocopilla quisiera informar de una situación que nos perjudica como colonia china respetuosa del país al cual han allegado"45.

El reclamo expresaba que dicha agrupación artística tenía en su espectáculo un espacio para un monólogo, llamado justamente "Chung Hwa", performance que desarrollaba "imitando en forma maliciosa nuestro idioma dejando en ridículo a nuestro pueblo. Siempre se ha desempeñado igual acto en el teatro (...) se ofenda así paisanos chinos i junto con ello a la colonia que presido. Esta denuncia busca

44 La Prensa (Tocopilla) 7 de agosto de 1929.

45 Archivo Provincial de Tocopilla, carta s/n Al Sr. Gobernador. Remite: J. Chang, 12 de junio 1932. 
detener lo que ridiculiza ofende y menoscaba nuestra dignidad de ciudadanos chinos respetuosos de este país"46.

El dirigente chino solicitaba que se tomaran medidas de restricción o censura a dicho espectáculo de menoscabo. El mismo reclamo fue enviado al alcalde Ignacio Rencoret el 15 de julio de 1932, A quien se le indicó que el autor del monólogo, el Sr. Macaya,

realiza monólogos burlescos diciendo que somos sucios i jugadores de azar en garitos. Además, intenta hablar como chino con el único propósito que el público se ría a carcajadas (...) Hemos buscado ayuda para frenar estas hirientes situaciones, pero solo he de hallar oídos indiferentes. Rogamos a usted señor alcalde pueda ayudar a detener esta injusta imagen que se difunde contra ciudadanos chinos ${ }^{47}$.

La respuesta a estas acusaciones la comunicó el gobernador Peralta, quien optó por censurar a la agrupación Los Criollos: "hemos comprobado sus acusaciones que además de considerarlas inaceptables y molestosas, hemos decidido cancelar las veladas definitivamente ante la negativa del director del conjunto de retirar el monólogo llevado a cabo por el señor Carlos Macaya"48.

Este dato resulta relevante porque constituye una demostración de fuerza y de injerencia de una colectividad que ha logrado construir alianzas y reconocimiento más allá del discurso xenófobo. ¿Qué habrá llevado a este cambio o correlación de fuerzas de acción? A esas alturas, otros centros Chung Hwa a nivel nacional ya estaban adquiriendo una visibilización positiva por efecto de las donaciones que realizaban. El diario de circulación nacional La Nación (Santiago) informaba que, en el marco del aniversario de la República China, "La Sociedad de Beneficencia de la Colonia Chung Hwa acordó conmemorarlo haciendo una donación a favor de los hospitales" 49 . El donativo consistía en 100 pesos para los principales hospitales de Santiago, tales como el Hospital San Vicente de Paul, el San José, San Juan de Dios, San Borja Arriarán, El Salvador y la Casa de Orates. El Centro Chung Hwa de Antofagasta ya había donado el portal del Cementerio General en 1910, en el marco del Centenario de la República de Chile, además de variadas donaciones durante el año 1915 (Banco Interamericano de Desarrollo, BID, 2004). Hacia 1927, el diario La Nación indicaba: "En Chile la colonia china alcanza a dos mil doscientas personas más o menos, todas comerciantes"50. Para el terremoto de 1928, el conjunto de comunidades chinas en Chile donó más de 10 mil pesos para aportar a la reconstrucción de la zona centro del país. Antecedente no menor, si se considera que el salario promedio en ese tiempo no superaba los 30 pesos (Bao, 2013). Y en

46 Archivo Provincial de Tocopilla, carta s/n Al Sr. Gobernador. Remite: J. Chang, 12 de junio 1932.

47 Archivo Provincial de Tocopilla, carta s/n Al Sr. Alcalde Rencoret Remite: J. Chang, 15 de julio 1932.

48 Archivo Provincial de Tocopilla, Oficio №17, Al Sr. Chang. Respuesta de Gobernador Peralta, 12 de agosto de 1932.

49 La Nación (Santiago) 9 de octubre de 1929.

50 La Nación (Santiago), 11 de octubre de 1927. 
Iquique, la misma agrupación fundada en 1893, el 2 de marzo de 1932 organizaba el Club Deportivo Chung Hwa, destacando en la práctica del basquetbol ${ }^{51}$.

Entonces, podemos ver que la comunidad china reprodujo en Chile una lógica étnicamente legitimada que se basa en estructuras de reciprocidad propias de la lógica del don. Momento en el cual el acto de dar no es solo una iniciativa de generosidad espontánea y desprovista de interés, sino también una marca de superioridad (Mauss, 2008). No cualquiera es quien dona, sino aquel que exhibe el poder y el capital necesarios para hacerlo, y con su donación de alguna forma apabulla a quien no tiene esos medios. Mecanismo que construye jerarquías y fundamenta de paso las distinciones internas, en tanto el reconocimiento de un tercero -en este caso la autoridad nativa- es necesario para obtener legitimidad entre las comunidades chinas de ultramar.

Se trataría de una forma arcaica de la lucha por el reconocimiento, que implica la aceptación primera de una identidad y una alteridad. El don operaría en este caso como el mecanismo del reconocimiento del otro, de su posición, del lugar que le corresponde en tanto otro. En este aspecto, los vínculos entre ambos tipos de derecho, el arcaico y el moderno, representan un desafío aún solo tenuemente estudiado (Flahaut, 2004; Anspach, 2004).

Así, el centro Chung Hwa de Tocopilla fue legitimando su presencia a través de diversas actividades. Por ejemplo, en la década de 1940 la celebración del Año Nuevo Chino fue otra forma de visibilizar a la colectividad, así quedó registrado ante una autorización que entregó el alcalde comunista Víctor Contreras Tapia en verano de 1943: "se autoriza cierre de calle 21 de mayo para la celebración de año nuevo chino y paseo de comparsas por la avenida citada. Esta repartición coordinará con el Cuerpo de Carabineros la seguridad de dicha celebración tan importante para su colonia"52.

El Chung Hwa de Tocopilla estuvo compuesto por chinos y sus descendientes, estos últimos crearon el Cheng Ning Hui. En conjunto, ambos grupos participaban activamente en la iglesia católica, muchos de los hijos de chinos y chinas se casaron con el ritual católico, además, muchos de ellos militaron en partidos políticos de derechas y como agrupación, siguieron usando la bandera nacionalista del Guomindang durante la década de $1960^{53}$ (ver figura 1).

51 El diario La Nación (Santiago) comenta el 12 de agosto de 1933 el abultado triunfo de la colectividad sobre el equipo Carampangue.

52 Archivo Gobernación de Tocopilla, Copia de Oficio municipal №94, 21 de enero 1943.

53 La alianza entre las comunidades chinas del norte de Chile con la Iglesia Católica y los partidos políticos de la derecha local ha sido reafirmada por Palma y Montt (2017). 
Migración china en Tocopilla. Heterogeneidad relacional y transformaciones internas (Chile, 1884-1960) por Damir Galaz-Mandakovic y Jorge Moraga R.

\section{Figura 1}

Los integrantes del Centro Chung Hwa de Tocopilla fueron cercanos a partidos políticos conservadores y católicos, no reconocieron a la República Popular China de Mao Mao Tse-Tung y siguieron usando la bandera nacionalista en todas sus ceremonias oficiales. La fotografía superior corresponde al año 1962. La fotografía inferior corresponde Alfredo Cam Ku (n.1901-f.1971) dueño de la tienda La Perla. Archivo de Yuksin Cam Loo.
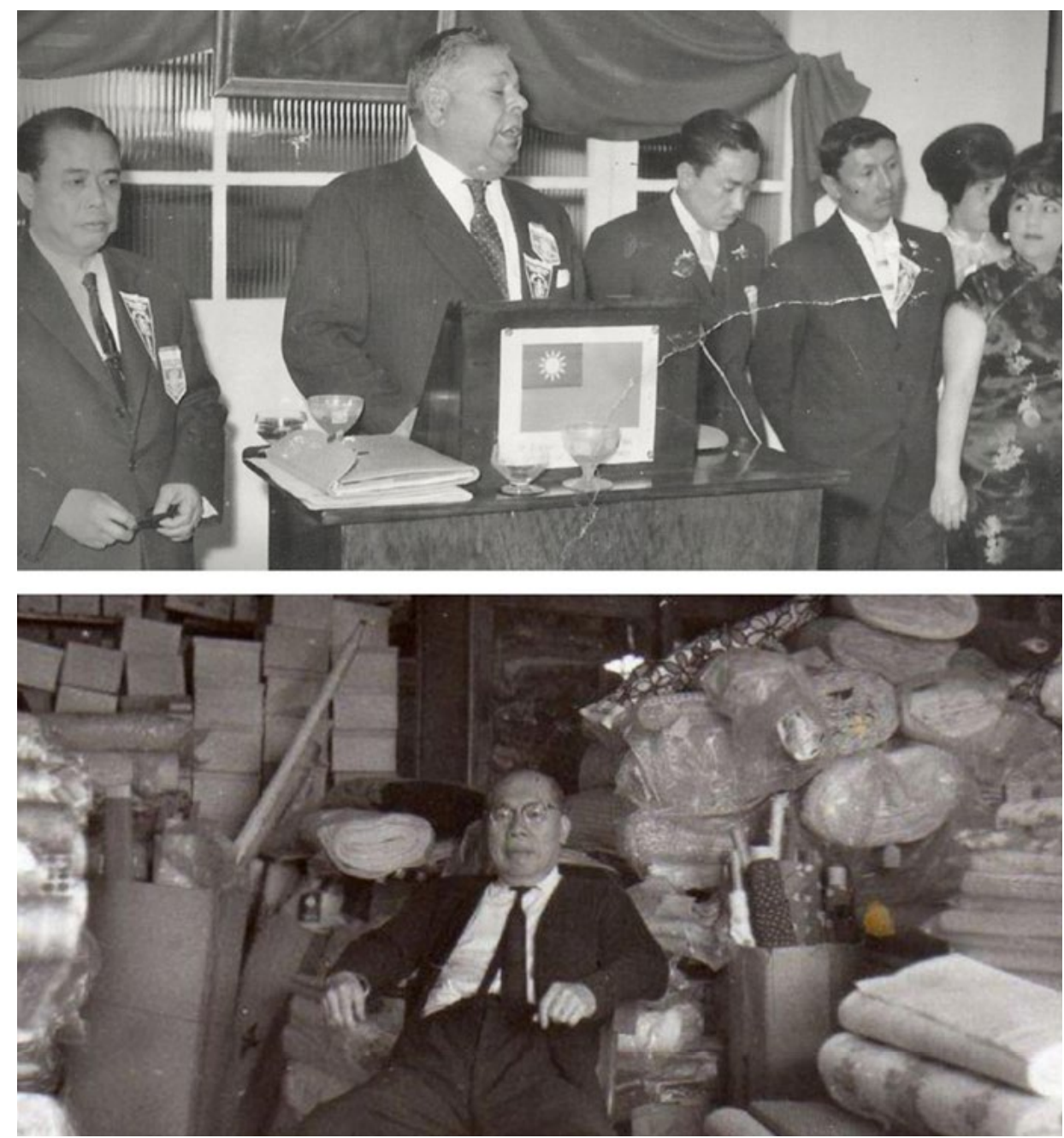


\section{Comercio y distinción}

Si hasta el momento los documentos recorridos nos muestran un mundo chino en el cual las jerarquías aún se encuentran principalmente en construcción y en disputa, en tanto la lucha por la hegemonía del campo mantiene una multiplicidad de posiciones de poder, representadas por una dispersión de "grandes hombres", o al menos en pugna por ser así reconocidos, esta escena claramente decantó a partir de la crisis de 1929, cuando una parte no menor de los asentados en el norte salitrero se vieron obligados a buscar nuevos horizontes, principalmente con la ilusión de instalarse en Santiago. Ese movimiento migratorio explica en buena medida la primera gran expansión de la colonia china en la capital del país, donde hasta ese momento había sido menor. Buscando este destino, no fueron pocos quienes se fueron insertando en ciudades intermedias (Bao, 2013). Pero, siguiendo una lógica de poder constatada también en sociedades segmentarias (Sahlins, 2010), en la década de 1930 la misma crisis del grupo en la globalidad de la zona salitrera -pues el cierre de salitreras conllevó la inviabilidad de muchos proveedores y comercios asociados- derivó en la consolidación de solo algunos "grandes hombres" y sus familias, quienes vieron un campo abierto, sin mayor competencia para su expansión, riqueza y lucimiento ante el nativo y también ante su propia colectividad..$^{54}$

Ese tiempo de "grandes hombres" marca hasta hoy un "esplendor mítico" de la migración china en Tocopilla y fue acompañado del gasto conspicuo de su élite, heredera, por cierto, de habitus y linajes anteriores. Nombraremos a los más destacados. Santiago Chiong construyó en 1932 un gran local para implementar su almacén especializado en la venta de carnes. Jon Chau levantó un edificio e instaló un restaurante, un prostíbulo, dos peluquerías y un cabaret con una gran pista de baile, local de entretención denominado como El Asia, icono de la vida nocturna. Guillermo Chang apostó con un almacén llamado San Pedro en calle Bolívar. Arturo Tang, quien nació en Cantón y llegó a los 17 años a lquique, se trasladó al poco tiempo a Tocopilla donde tuvo una carnicería, administró un cabaret y fue propietario de una tienda llamada Victoria en calle 21 de mayo esquina Bolívar. Alfredo Cam Ku llegó desde el Perú, en Tocopilla instaló una verdulería y diversificó su negocio hacia los alcoholes, instaló también una carnicería mayorista, seguidamente inauguró la tienda llamada La Perla. Por su parte, Kai Lau Chau instaló un gran almacén con ventas de abarrotes y diversidad de víveres, le seguiría la implementación de una carnicería. En 1939, Ramón Young adquirió la tienda de géneros Ukrania perteneciente a la familia Jodorowsky (Galaz-Mandakovic, 2013, p.102). En ese mismo año, el semanario tocopillano 4 de junio publicó que Federico Cam era un importante proveedor de carne en la ciudad, y que contaba con 5 carnicerías cuya particularidad era: "Atención esmerada, peso exacto y personal especial de cajeras"55.

54 Es necesario recordar aquí la analogía con los big-men señalados por Sahlins en la Melanesia, a quienes compara y contrapone con la más compleja estructura política polinesia, compuesta por "linajes rankeados". Sahlins considera análoga la estructura polinesia a los clanes chinos tradicionales (Sahlins, 1963, p.287).

554 de junio (Tocopilla) 4 de junio de 1939. 
Siguiendo ese mismo impulso, en el año 1944, algunos chinos figuran en los listados de la Sociedad de Comerciantes Minoristas, institución fundada el 10 de agosto 1931. Entre ellos aparecen: Ramón Young, Antonio Tong, Ernesto Loo, Jose Lan, Alfredo Cam, Carlos Chong, José Segundo Chiong y Celia Chia ${ }^{56}$.

Como una derivación negativa de este momento marcado por el consumo conspicuo y el gasto agonístico, muchos de los emprendimientos chinos que incluían la importación de artículos suntuarios fueron víctimas habituales de robos. Por citar un par de ejemplos: Juan Chang denunció en la Comisaría de Investigaciones que a las 3:30 am del 25 de junio de 1946 "extraños habian penetrado a su negocio, por lo que hizo un inventario pudiendo darse cuenta de que le habian sustraído más o menos 50 relojes de diferentes marcas y calidad (...) por el momento calcula el valor de los sustraído en \$19.000"57. Por su parte, Santiago Chiang Chong denunció que en su domicilio habían robado varios ternos y "la cantidad de tres mil pesos en dinero efectivo" 58 . En ambos casos, los ladrones ingresaron por los tragaluces.

\section{Figura 2}

Publicidad de dos negocios emprendidos por chinos desde finales de la década de 1940. Fuente: Semanario La Cosa, junio de 1954.

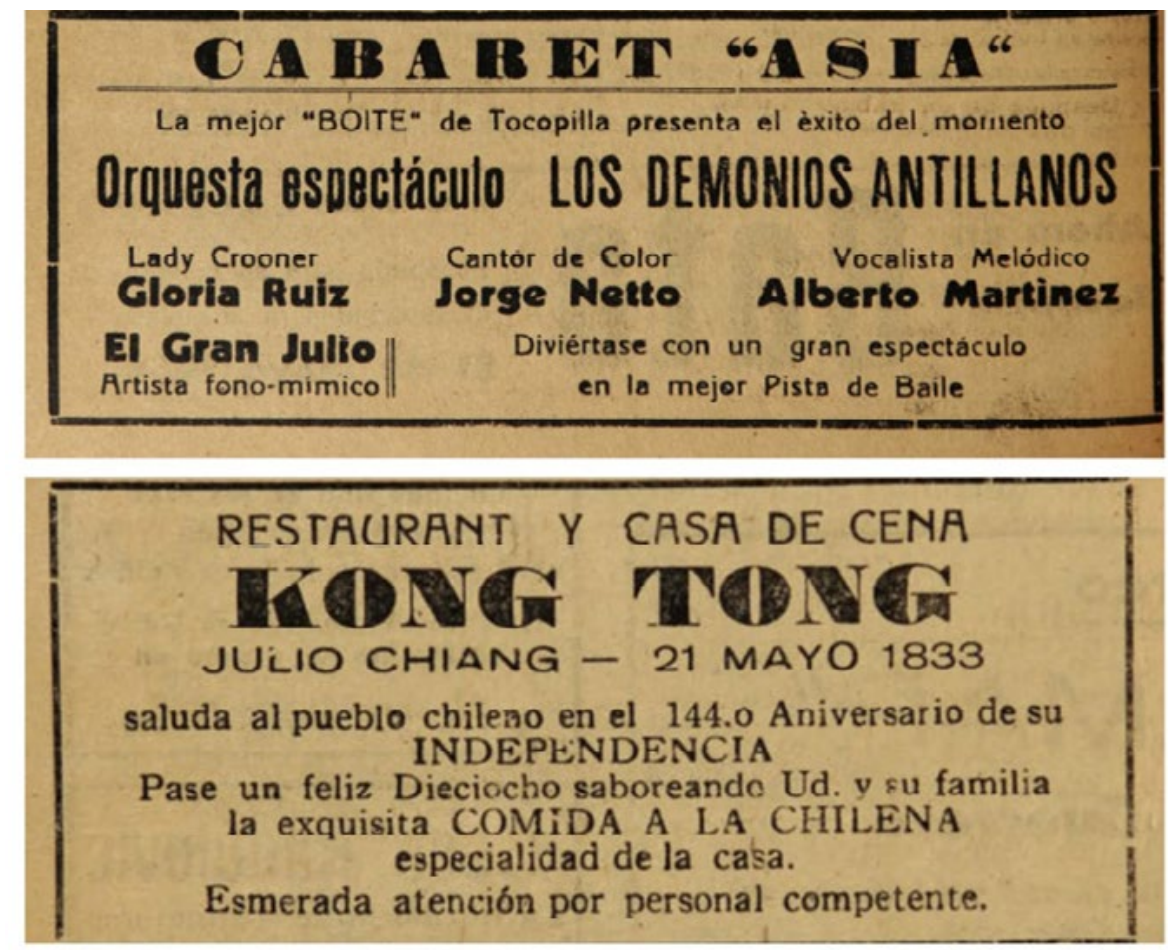

56 Archivo Gobernación de Tocopilla, Acta de sesión de la Sociedad de Comerciantes Minoristas, 3 de marzo de 1944.

57 Archivo Gobernación de Tocopilla, Policía de Investigaciones, Comunicación de novedades № 144, 25 de junio de 1946.

58 Archivo Gobernación de Tocopilla, Policía de Investigaciones, Comunicación de novedades № 230 , 11 de octubre de 1946. 
En este grupo de comerciantes chinos, existe un caso notable: Arturo Chau Ly (Figura 3).

En el tenor del desmantelamiento de las salitreras del sistema Shanks se desarticularon los flujos de la venta de animales y de las carnes muertas en la pampa. No obstante, con el surgimiento de las salitreras del sistema Guggenheim, tales como María Elena en 1926 y Pedro de Valdivia en 1931, sería un ciudadano chino el que usufructuaría de ese mercado de las carnes que se abría. Hablamos de Arturo Chau Ly, quien había arribado a Antofagasta desde la provincia de Guangdong en 1914 y después de vivir en algunas salitreras, se instaló definitivamente en Tocopilla. El diario La Prensa en la edición del 7 de enero de 1935 publicitaba lo siguiente: "Arturo Chau Ly: proveedor de ganado en Tocopilla y en los puestos de las Oficinas salitreras de María Elena, Pedro de Valdivia, José Francisco Vergara y Coya Sur. Carne de Novillos de Primera Clase y Entrega a Vapores. Ventas al por mayor y menor" 59 .

Este ciudadano cantonés, en el marco de la proveeduría de carnes, articuló un sistema de flujo de animales desde el norte de Argentina, en especial desde Salta, participando en el mercado de las carnes de primera clase (novillos), de segunda clase (bueyes) y de tercera clase (torunos) ${ }^{60}$. Por citar un par de ejemplos, en abril de 1944, Chau Ly faenó 193 vacunos, 103 lanares y 46 caprinos $^{61}$. En mayo del mismo año, faenó 152 vacunos, 91 lanares y 95 caprinos $^{62}$.

Siguiendo la lógica esperada en sus prácticas culturales, Arturo Chau Ly fue transformándose en un filántropo local. Su nieto Ilamado Chimeng Chau, nos dice:

Mi abuelo fue presidente de la Cámara de Comercio, cooperó con la compra de carros para los bomberos, financió paraderos de microbuses, ayudaba seguidamente a la Cruz Roja, uniformes para el Orfeón Musical de la municipalidad, cooperaba con dinero en Chile Sporting Club (...) le daba empleo a más de 100 personas en Tocopilla. También fue presidente honorario del Club Deportivo Palestino de Tocopilla, tuvo una flota de camiones ${ }^{63}$.

El Patronato de la Infancia también supo de sus contribuciones como así también la iglesia católica y el Hospital Marcos Macuada.

Una obra por la cual sería recordado Chau Ly, fue la donación de un parque infantil de $1.000 m 2$ en el año 1944, el que contaba con un conjunto de columpios, balancines, una pasarela y un carrusel, con capacidad para 200 niños, parque que incluyó una plaza. El diario La Prensa tituló:

59 La Prensa (Tocopilla) 7 de enero de 1935.

60 Archivo Gobernación Provincial de Tocopilla, Decreto №12, Comisariato Departamental de Subsistencia y Precios, 22 de julio de 1939.

61 Archivo Gobernación Provincial de Tocopilla, Doc. №81, Sobre producción de cueros. Al Sr. Comisario general de Subsistencia y Precios, 5 de mayo de 1944.

62 Archivo Gobernación Provincial de Tocopilla, Doc. №95l, Sobre producción de cueros. Al Sr. Comisario general de Subsistencia y Precios, 5 de junio de 1944.

63 Chimeng Chau, comunicación personal, 26 mayo de 2018. 
Ante numeroso público y con la asistencia de las autoridades fue inaugurado ayer el Parque de Juegos Infantiles Arturo Chau Ly"64. La obra que tuvo un costo de \$30.000 fue para "obsequiar estos juegos a los hijos del pueblo de Tocopilla (...) forma de agradecer en parte el afecto y la hospitalidad que debo al pueblo de Chile ${ }^{65}$.

\section{Figura 3}

Arturo Chau Ly, nacido en Guangzhou, llegó a ser proveedor de ganado en todo el Departamento de Tocopilla en especial de las Oficinas salitreras y de los barcos que recalaban en el puerto local. Según el semanario 4 de Junio (Tocopilla) en 1939 el ganado no solo provenía desde Argentina, sino que también desde el sur de Chile. Contaba con cinco carnicerías en el puerto y una flota de camiones para el traslado de la carne hasta la pampa salitrera. Hacia 1965, un club futbolístico de la Liga Federada de Tocopilla Ilevó su nombre. Archivo: Yuksin Cam Loo.

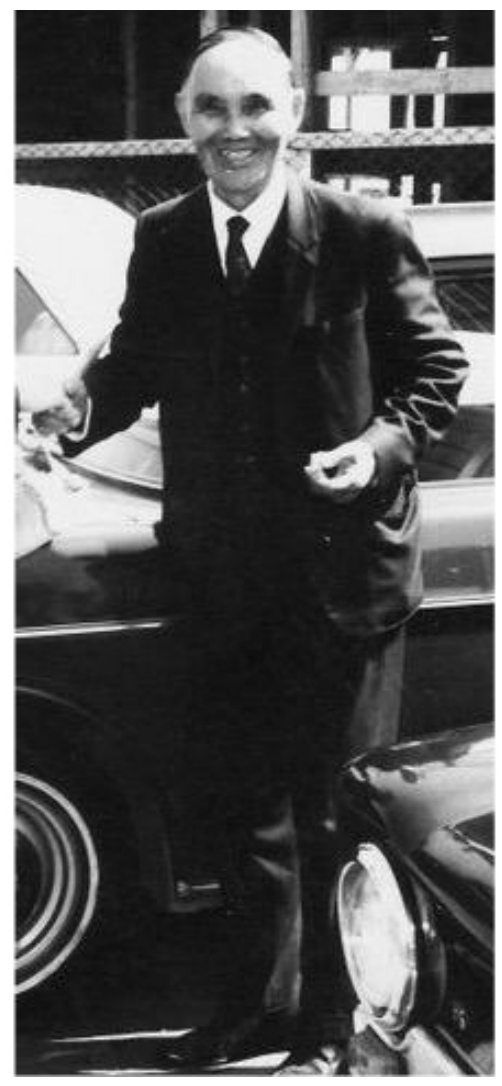

En la misma lógica del don, enfatizando la conformación de deudas no explícitas pero que esperan -a partir de su gratitud- una retribución sin tiempo fijo, es posible mencionar otros ejemplos que dan cuenta de la continuidad de prácticas relacionadas con esa lógica en décadas siguientes. Como resulta obvio, se trata de una superioridad no sólo económica, sino social y moral que refuerza la autoridad del donador. Quien recibe lo dado acepta los términos de dicho acuerdo, cuya amplitud

64 La Prensa (Tocopilla) 25 de diciembre de 1944.

65 La Prensa (Tocopilla) 25 de diciembre de 1944. 
y contenidos dependerán sólo de quienes lo reconocen y se benefician de él. Se trata, por lo mismo, de una relación de poder y respeto que se legitima a partir de acuerdos particulares. La lógica presente en él estaría basada no en la abstracción de la ley, aunque puede operar en su interior, sino en relaciones concretas fundadas en el juego ambivalente de la solidaridad y de la lucha, del reparto igualitario y la competencia agonística, presentes en este tipo de lazo social. ${ }^{66}$

Así, podemos ver que en 1943 el gobernador de Tocopilla agradecía al centro Chung Hwa por un cheque de $\$ 1.000$ pesos para los damnificados de Calbuco, comunidad que había sufrido un gran incendio el 31 de enero de 1943, en el que resultaron quemadas 12 manzanas con viviendas. El gobernador Márquez dijo: "eterna gratitud y respeto para los integrantes del Centro Chung Hwa donantes"67.

Donativos importantes en el mismo año fueron entregados a instituciones caritativas, como el Comité Pro Pascua de los Niños Pobres de Tocopilla, acción agradecida por uno de los gestores, el Gobernador Departamental de Tocopilla Pedro Muñoz Rojas, quien indicó:

Señor Roberto Ly Cere, Presidente del Centro Chung Hwa de Tocopilla: Permítame señor Presidente (...) testimoniarles una vez más el reconocimiento de gratitud hacia su institución, ya que siempre ha estado atento a las peticiones de esta Gobernación, contribuyendo gustoso y ampliamente a cuánta obra de bien se ha iniciado en la ciudad, siendo un ejemplo para las demás instituciones. Es por ello que reiteramos nuestros agradecimientos por la ayuda prestada al Comité Pro Pascua de los Niños Pobre de Tocopilla68.

Este devenir de donativos, nuevamente se expresaría en verano de 1944, el nuevo gobernador Adolfo Márquez agradecía en un documento la donación de dinero de la agrupación Chung Hwa:

Esta repartición pública que dirijo agradece vuestro gesto y el de su distinguida colonia para con nuestros niños de Tocopilla y también con los de las Oficinas Salitreras de María Elena, José Francisco Vergara y Pedro de Valdivia, quienes pudieron celebrar una grata navidad junto a sus familias. El Comité Pro Pascua para Niños Pobres agradece la entrega de vuestra ayuda económica para socorrer a dichas almas maltratadas por la vida y la pobreza. Hago votos por la ventura personal de los ciudadanos chinos residentes en Tocopilla, y muy especialmente por Ud.69

66 Resulta aquí inevitable la "primitiva" comparación maussiana: "Un jefe no conserva su autoridad [...] más que si prueba que está embrujado y favorecido por los espíritus de la fortuna, que es poseído por ella y que él la posee; y no puede probar esa fortuna más que gastándola, distribuyéndola, humillando a los otros, poniéndolos 'a la sombra de su nombre'” (Mauss, 2008, p.206).

67 Archivo Gobernación Provincial de Tocopilla, Oficio №247, Al Sr. Presidente Chung Hwa. Remite: Gobernador Márquez, 31 de marzo de 1943.

68 Archivo Gobernación Provincia de Tocopilla, Oficio №741, Al Sr. Presidente Centro Chung Hwa, 1 de diciembre de 1943.

69 Archivo Gobernación Provincia de Tocopilla, Oficio №89, Al Sr. Presidente Centro Chung Hwa, 12 de enero de 1944. 
En los hechos, podemos cerciorar que el Centro Chung Hwa fue un activo colaborador del Estado en su nivel departamental, contribuyendo en diversas agencias asistencialistas de varios ámbitos para la población. Fue también el espacio para que algunos chinos articularan acciones para obtener una cara (mianzi-面子) que, en el decir de Goffman, deviene en: "el valor social positivo que una persona afirma de sí misma por la forma que otros asumen que él ha tomado durante un contacto particular. Cara es una imagen del si mismo delineada en términos de atributos sociales aprobados" (Goffman, 1955, p.213). No cabe duda de que la búsqueda y construcción de una cara o mianzi-面子 es la principal fuente de diferenciación y posicionamiento social en el mundo chino (Goffman, 1955; Ho, 1976; Hwang, 1987; Yan, 1996; Earley, 1997; Beltrán, 2003; Moraga, 2012, entre otros).

\section{Figura 4}

Colonia china frente al edificio del Centro Chung Hwa en la celebración del aniversario de China en 1961, además de las fuerzas policiales acompaña el alcalde Julio Fernández Jiménez y el gobernador Adolfo Márquez. Abajo: exposición de arte chino en 1962, actividad liderada por las mujeres del Centro Chung Hwa. La siguiente fotografía corresponde a integrantes de la colonia, entre ellos: Simón Lonking, Simon Lau, Alonso Siu, Edith Chia, Jorge Chau, Sra. Lonking, Arturo Tan, Ramon Tama, Santiago Chau, Fresia Jaug, Alfredo Cam, Vinko Yap y Federico Loo. Archivo de Moy-San Tang.
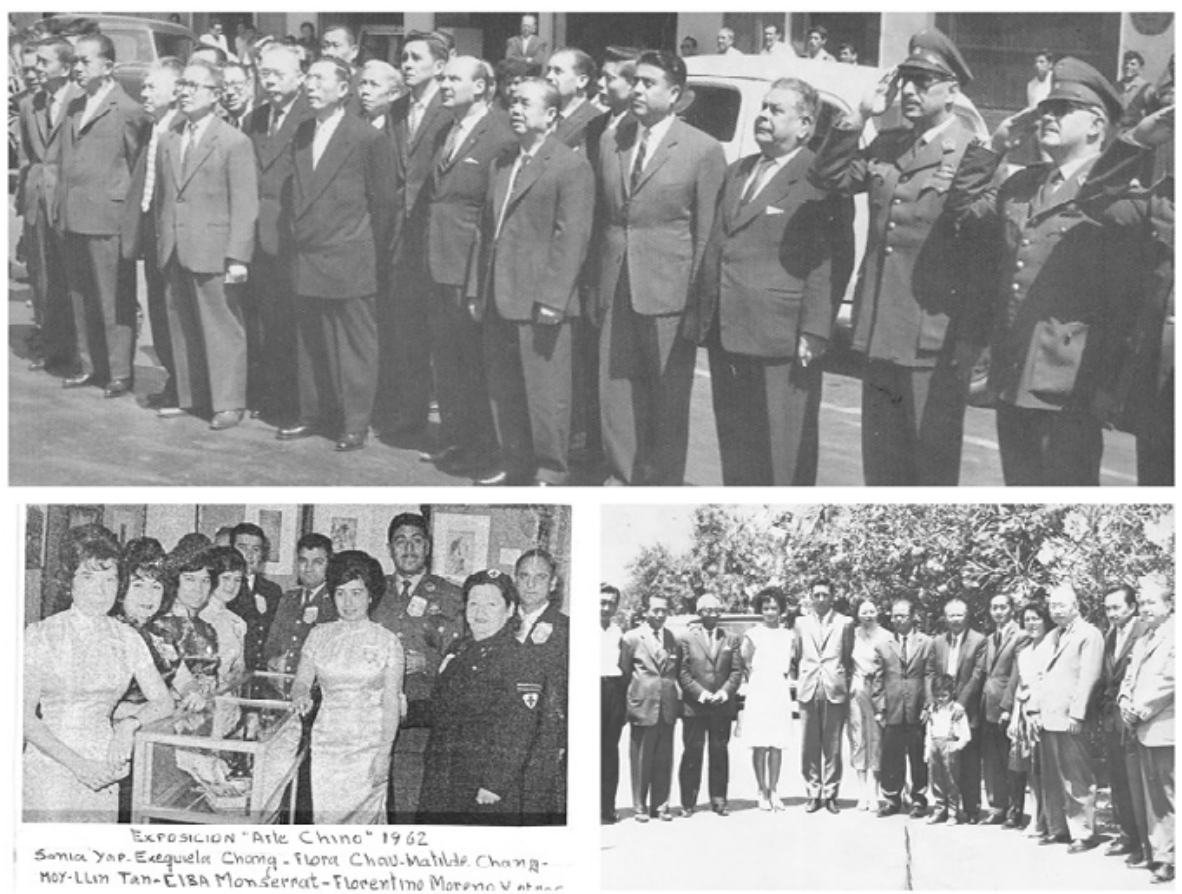


\section{Figura 5}

Integrantes el Centro Chung Wha de Tocopilla en 1955, entre ellos: Carlos León, Felipe Ly, Federico Loo, Arturo Chau, Alfredo Cam, Ramón Young, Alonso Siu, Julio Chiang, Santiago Chau, Tan Jau, Guillermo Chang, Emilio Lau, Cam Fox, Roberto Hafón, Tomás Wong. Los lujosos y nuevos automóviles en manos de ciudadanos chinos fue también un sello de distinción en un contexto de pobreza y de escasas calles pavimentadas, como así también el uso de ternos y corbatas en su vida cotidiana. Abajo: Matrimonio entre hijos de chinos residentes en Tocopilla, evento realizado en el Club de la Unión en 1961. Archivo de Moy-San Tan.
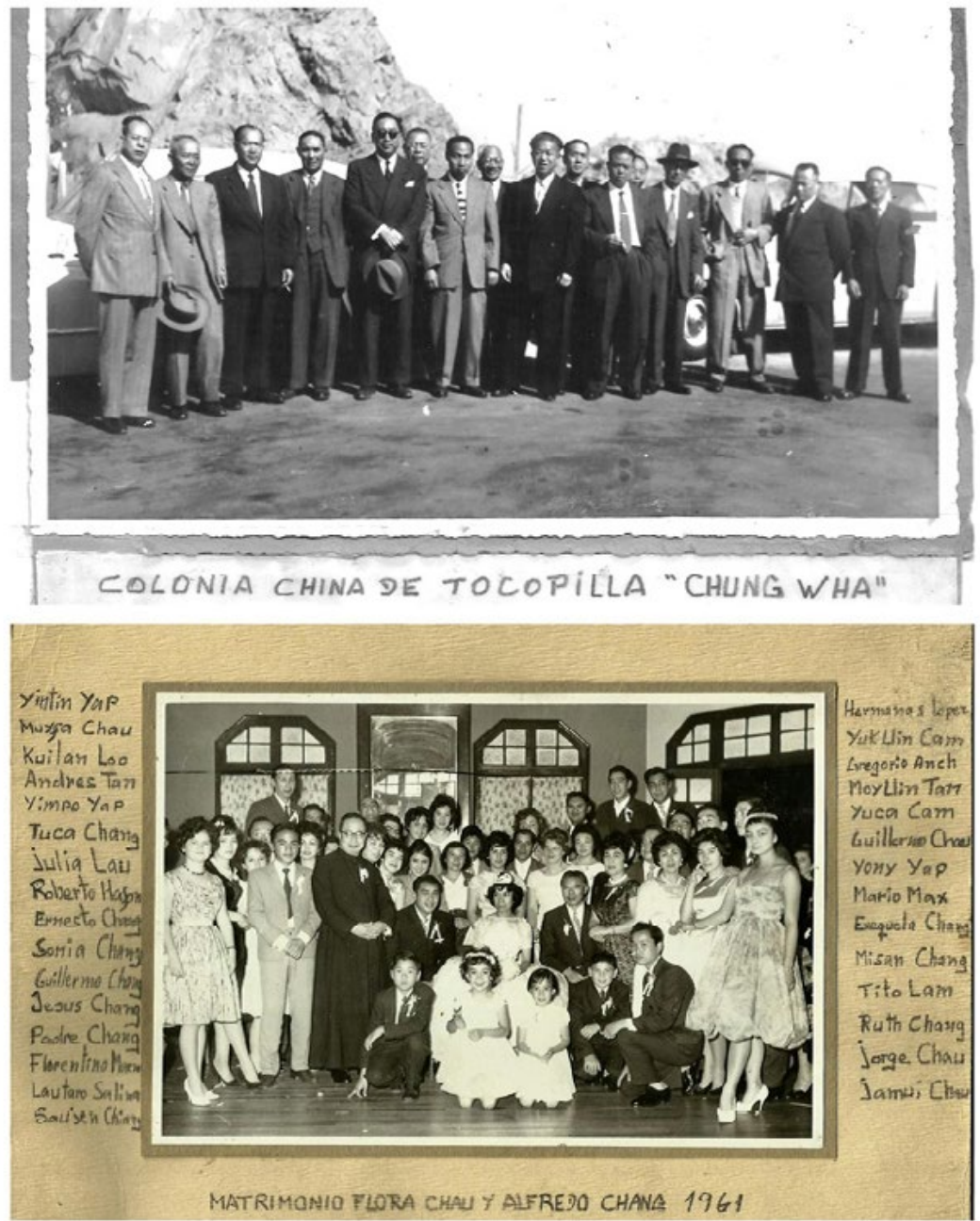


\section{Disonancias}

Simultáneamente a estos engrandecimientos de la imagen de la colonia, ocurrían algunos hechos que remiten a cierta disonancia y heteroclicidad por parte de otros migrantes chinos. Solo por citar algunos ejemplos, podemos ver que algunos chinos siguieron percibiendo cierta hostilidad. Tenemos el caso de un migrante situado en la pampa salitrera, Juan Chau, quien fue multado por el Comisario Departamental de Subsistencia y Precios en la Oficina María Elena:

siendo las 17 horas, notifiquéal comerciante chino Juan Chau, domiciliado en esta Oficina, el Decreto № 29 de ese comisariato, en el que se le condena a pagar una multa de cincuenta pesos (\$50.-) por infringir las disposiciones del Comisariato Departamental de Subsistencia $y$ Precios, al vender artículos de primera necesidad a un precio mayor $y$ por no dar el peso legítimo del kilo ${ }^{70}$.

También nos encontramos con el caso de Ramón Kong, comerciante de carnes, quien denuncia cierta persecución por parte de Santiago Ferrús López, miembro de la Junta de Vigilancia del Comisariato de El Toco, quien desde hace algún tiempo,

se ha presentado a su negocio para exigirle Cajera y, como él no la tiene, le ha obligado le dé $\$ 60$ pesos mensuales por tolerar la falta de esta empleada (...) que el señor Santiago Ferrús López ha recibido durante varios meses esta cantidad de $\$ 60$ pesos y que a menudo lo sigue molestando ${ }^{71}$.

También está el caso de algunas quejas ante la supuesta ludopatía china y el jolgorio asociado, así lo mencionaba el gobernador en un documento enviado a Carabineros:

Esta Gobernación ha recibido numerosos reclamos por parte de vecinos que habitan la calle 21 de mayo en las cercanías del edificio de la colonia china Chung Hwa. Los vecinos han expresado a esta repartición pública que todos los dias se escuchan gritos, escándalos y se consumen bebidas alcohólicas a saber de las restricciones que ha aplicado el Grupo Comando de Defensa de Costa"72.

Las quejas de vecinos anónimos estaban referidas a que en el inmueble del centro Chung Hwa existía un garito donde, "connotados ciudadanos y comerciantes

70 Archivo Gobernación Provincial de Tocopilla, Decreto №144, Subdelegación de El Toco, María Elena, 5 de diciembre de 1939

71 Archivo Gobernación Provincial de Tocopilla, Oficio №342, Al Sr. Gobernador. Remite: Subdelegación Civil de Toco, Oficina María Elena, 6 de noviembre de 1941.

72 Archivo Gobernación Provincial de Tocopilla, Oficio №24, Al Sr. Comisario de Carabineros de Tocopilla. Remite: Gobernador. 13 de diciembre 1942. 
acuden todas las noches a jugar distintas apuestas" ${ }^{73}$. En esas circunstancias, se solicitaba una inspección policial y revisión de pasaportes ${ }^{74}$.

En 1944 también se denuncia la existencia de un matadero ilegal administrado por el ciudadano chino Iwan Ly Loo, quien fue sorprendido al Ilegar al hospital con las ropas manchadas con sangre. Ante el hecho, su casa habitación fue allanada, encontrando que: "había faenado varias gallinas, pero sin ninguna medida hijiénica. Al solicitar los permisos sanitarios respectivos, no pudo dar ninguna respuesta ante nuestros requerimientos. Pudimos ver que estábamos en presencia de un matadero clandestino"75. En dicha revisión también se realizó el hallazgo de 20 aves, 9 cabros y un cerdo pequeño. Dichos animales muertos tenían como objetivo ser comercializados en la población de la zona de la Manchuria y la zona de la Beneficiadora de Metales. El matarife chino fue detenido, y según el informe de Carabineros,

tiene fama de ser alcohólico y que había tenido buen pasar pero que por efecto de juegos y malas costumbres había perdido sus capitales y negocios, lo que motivó que su mujer se fuera con otro ciudadano chino con residencia en lquique, dejándolo irresponsablemente con su hijo de 5 años $^{76}$.

Más allá de estos hechos, las percepciones positivas serían un poco más hegemónicas, por ejemplo, en 1949, un estudiante de la Escuela Normalista de Copiapó, Enrique Campdelacreu, comentaba en su memoria de prueba:

La colonia china es la más numerosa dentro de la ciudad (...) sus miembros gozan de estimación en todos los círculos por la corrección de sus actos, la generosidad con que contribuyen a toda obra de bien social y el respeto que siempre han guardado a nuestras leyes y a nuestras autoridades ${ }^{77}$.

73 Archivo Gobernación Provincial de Tocopilla, Oficio №24, Al Sr. Comisario de Carabineros de Tocopilla. Remite: Gobernador. 13 de diciembre 1942.

74 Que las sedes de los Centros Chung Hwa fueran acusadas de ser lugares de juegos, no era novedad. En marzo de 1938, un gran operativo policial en Santiago detuvo a un centenar de chinos por "jugar y fumar opio", informó el diario La Nación, agregando: "Revólver en mano, los detectives penetraron al club social Chung Hwa ubicado en San Pablo 1571 (...) numerosos chinos lograron escapar por los tejados, causando verdadera alarma en el vecindario (...). Fueron puestos en libertad los detenidos previa comprobación de sus respectivos domicilios y depósito de 300 pesos de fianza cada uno quedando citados para comparecer..." (La Nación, 21 de marzo de 1938). Sobre el consumo de opio, el diario indicó que existía un segundo piso donde los chinos se recostaban en camarotes "hasta cuyas cabeceras llegaban las mangueras que partían desde el quemador" (La Nación, 21 de marzo de 1938). La difusión de este tipo de noticias, muchas de ellas con detalles caricaturescos, ayudaron a reproducir una gran cantidad de estereotipos y prejuicios orientalistas.

75 Archivo Gobernación Provincial de Tocopilla, Oficio №23, Dirección General de Investigaciones, A/ Sr. Gobernador, 10 de marzo de 1944.

76 Archivo Gobernación Provincial de Tocopilla, Oficio №23, Dirección General de Investigaciones, A/ Sr. Gobernador, 10 de marzo de 1944.

77 Campdelacreu, 2009 [1949], p.47. 
Estos procesos de percepción positiva se incrementaron desde la segunda mitad de la década de 1950 por efecto de una serie de eventos, tales como las fastuosas fiestas en el elitista Club de la Unión, los suntuosos matrimonios, las fiestas juveniles del Cheng Ning Hui, las fiestas infantiles, las celebraciones del Aniversario de China, las exposiciones de Arte Chino, entre otras actividades.

A pesar de estos procesos de elitización, siguieron existiendo chinos que se vincularon con cierto lumpen local. Así lo menciona un documento confidencial de la Dirección General de Investigaciones en septiembre de 1954, institución que sorprendió al chino Eduardo Kam Fu, 36 años de edad, quien disponía de una taberna ilegal en su casa, "domicilio sobre el cual existían sospechas de consumos de narcóticos además de ser un lugar de apuestas ilegales y venta de licores sin patentes"78. Al momento del allanamiento, Kam Fu estaba acompañado de "personajes reputados del lumpen de la localidad quienes también estaban borrachos y dos de ellos estaban armados con revólver no inscritos"79. Estos ciudadanos fueron acusados de contrabando de narcóticos, consumo en taberna ilegal, porte de armas prohibidas y ofensas a la moral.

\section{Transacciones inmobiliarias}

En el contexto del arraigo territorial que establecieron los migrantes chinos en el puerto salitrero de Tocopilla, estos, en el marco de la elitización de algunos integrantes del colectivo, comenzaron a participar en las dinámicas de compraventa de inmuebles. De ese modo, varios chinos devinieron en destacados propietarios. Gracias a los archivos históricos del Ministerio de Bienes Nacionales, rescatados en la Gobernación Provincial de Tocopilla, fue posible hallar un registro de diversas transacciones de propiedades entre los años 1938 y 1959 y de ese modo, construir una base de datos, todo esto en el marco de la misión institucional del Ministerio citado que busca reconocer, administrar y gestionar el patrimonio fiscal de todos los habitantes de Chile ${ }^{80}$.

Así, en el rango cronológico de 1938 a 1959, fue posible identificar 121 acciones realizadas por ciudadanos chinos en un universo de 3.783 registros de propiedad. En ese sentido, fueron las compraventas las acciones más realizadas por los migrantes chinos en Tocopilla, representado el $83,4 \%$ en comparación a las transacciones o adjudicaciones de otro tipo (Tabla 1). De esta manera, los chinos demostraron que la elitización en cierto modo estaba remitida a la tenencia de propiedades.

\footnotetext{
78 Archivo Gobernación Provincial de Tocopilla, Oficio confidencial №21, Dirección General de Investigaciones, A/ Sr. Gobernador, 15 de septiembre de 1954.

79 Archivo Gobernación Provincial de Tocopilla, Oficio confidencial №21, Dirección General de Investigaciones, A/ Sr. Gobernador, 15 de septiembre de 1954.

80 A su vez, busca mantener el catastro gráfico de la propiedad fiscal actualizado y de esa manera regularizar la pequeña propiedad raíz particular. En ese sentido, la propiedad privada podemos entenderla como el derecho de las personas de obtener, emplear, poseer, controlar y disponer un espacio físico determinado, con la facultad de heredar según su acuerdo o contexto determinado.
} 


\section{Tabla 1}

Ranking de tipos y cantidades de transacciones de propiedad en manos de chinos entre 1938 y 1959. Fuente: Archivo Gobernación de Tocopilla, Registro de propiedades del Ministerio de Bienes Nacional para la ciudad de Tocopilla.

\begin{tabular}{|c|c|c|}
\hline Tipo de transacción & Cantidad & $\%$ \\
\hline Compraventa & 101 & $83,4 \%$ \\
\hline Herencia & 8 & $6.6 \%$ \\
\hline Partición & 3 & $2.4 \%$ \\
\hline Adjudicación en partición & 2 & $1.6 \%$ \\
\hline Posesión efectiva de herencia & 2 & $1.6 \%$ \\
\hline Título gratuito de dominio & 2 & $1.6 \%$ \\
\hline Adjudicación & 1 & $0.8 \%$ \\
\hline Aporte & 1 & $0.8 \%$ \\
\hline Inscripción especial de herencia & 1 & $0.8 \%$ \\
\hline Total & 121 & $100 \%$ \\
\hline
\end{tabular}

Elaboración propia

En ese cuadro, también podemos visualizar que gran parte de las acciones de transacción tuvieron años destacados, particularmente en 1946, año de mayor actividad. Adicionándose el año 1948, 1950, 1951 y 1952. Por su parte, los años donde menos actividades ocurrieron fueron 1942, 1945 y 1956 (Gráfico 1). 


\section{Gráfico 1}

Análisis cronológico de las transacciones de propiedad s entre 1937 y 1959 por parte de ciudadanos chinos. Fuente: Archivo Gobernación de Tocopilla, Registro de propiedades del Ministerio de Bienes Nacional para la ciudad de Tocopilla.

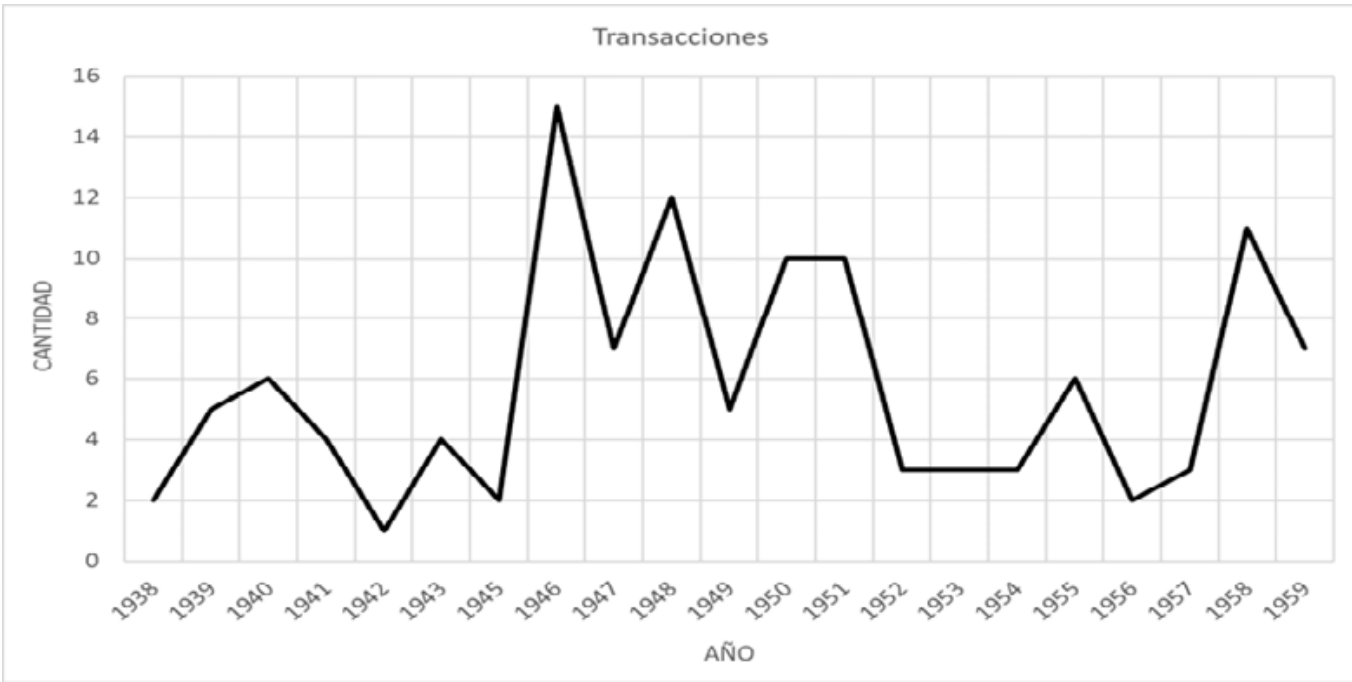

Elaboración propia

En estas transacciones participaban personas naturales y sociedades. Como se visualiza en la tabla 2, son los hombres lo que mayoritariamente están agenciando compraventas, con un total de 89 hombres chinos $(73,5 \%)$, significativa diferencia con las mujeres, quienes se contabilizan en $16(13,2 \%)$, cifra que dialoga proporcionalmente con el mismo porcentaje para las sociedades, las que normalmente eran mixtas (12,3\%). 


\section{Tabla 2}

Descripción de acciones realizadas entre mujeres, hombres y sociedades mixtas que participaron en el proceso de transacción de compraventas de propiedades entre 1938 y 1959. Fuente: Archivo Gobernación de Tocopilla, Registro de propiedades del Ministerio de Bienes Nacionales para la ciudad de Tocopilla.

\begin{tabular}{|c|c|c|c|c|c|}
\hline \multirow{2}{*}{ Año } & \multicolumn{4}{|c|}{ Sexo Propietario Actual } & \multirow{2}{*}{ Total } \\
\hline & hombre & mujer & sociedad & $\mathrm{s} / \mathrm{i}$ & \\
\hline 1938 & 2 & & & & 2 \\
\hline 1939 & 4 & 1 & & & 5 \\
\hline 1940 & 5 & 1 & & & 6 \\
\hline 1941 & 4 & & & & 4 \\
\hline 1942 & 1 & & & & 1 \\
\hline 1943 & 4 & & & & 4 \\
\hline 1945 & 2 & & & & 2 \\
\hline 1946 & 11 & & 4 & & 15 \\
\hline 1947 & 6 & 1 & & & 7 \\
\hline 1948 & 8 & 2 & 2 & & 12 \\
\hline 1949 & 3 & 2 & & & 5 \\
\hline 1950 & 8 & 1 & 1 & & 10 \\
\hline 1951 & 8 & 1 & 1 & & 10 \\
\hline 1952 & 3 & & & & 3 \\
\hline 1953 & 3 & & & & 3 \\
\hline 1954 & 3 & & & & 3 \\
\hline 1955 & 2 & 2 & 2 & & 6 \\
\hline 1956 & 2 & & & & 2 \\
\hline 1957 & 2 & 1 & & & 3 \\
\hline 1958 & 5 & 3 & 2 & 1 & 11 \\
\hline 1959 & 3 & 1 & 3 & & 7 \\
\hline Total & 89 & 16 & 15 & 1 & 121 \\
\hline
\end{tabular}

Elaboración propia 
El gráfico 2 demuestra que las mujeres tuvieron mayor participación en los años 1949, 1955 y 1957. Por su parte, las sociedades mixtas destacan en los años 1946, 1948, 1955 y 1959. Este último año el más significativo para las sociedades que transaron propiedades.

\section{Gráfico 2}

Comparación entre mujeres, hombres y sociedades mixtas que participaron en el proceso de transacción de compraventas de propiedades entre 1938 y 1959. Fuente: Archivo Gobernación de Tocopilla, Registro de propiedades del Ministerio de Bienes Nacionales para la ciudad de Tocopilla.

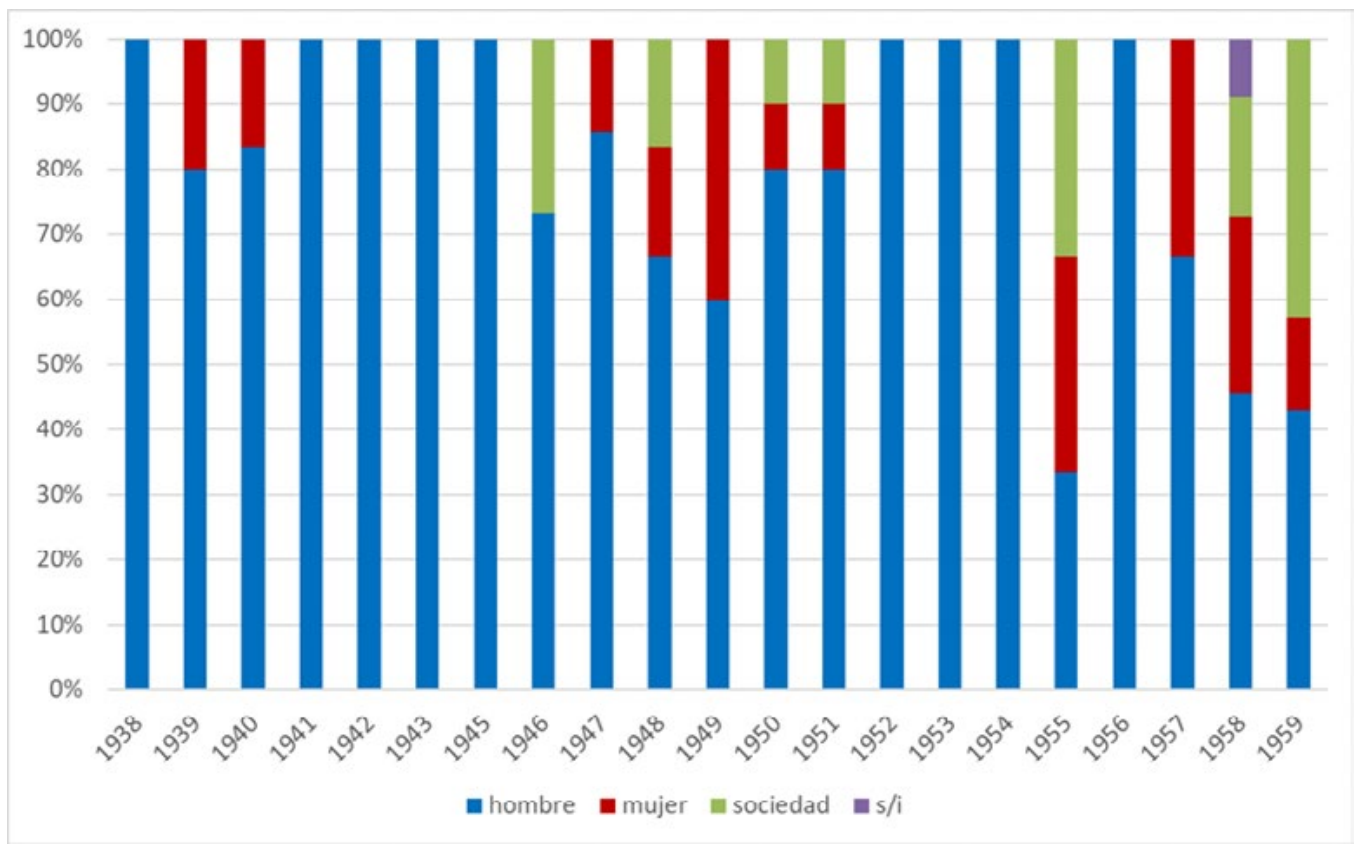

Elaboración propia

También es posible visualizar la cantidad de metros cuadrados movilizados por chinos y chinas en cuanto a propiedades que venden y propiedades que compran (Gráfico 3). Fue, entonces, el año 1950 cuando más metros cuadrados adquirieron estos migrantes. Y fue en el año 1946 cuando más propiedades se vendieron por parte de chinos y chinas. 


\section{Gráfico 3}

Cantidad de metros cuadrados movilizados por chinos y chinas en cuanto a propiedades que venden y propiedades que compran entre 1938 y 1959. Fuente: Archivo Gobernación de Tocopilla, Registro de propiedades del Ministerio de Bienes Nacionales para la ciudad de Tocopilla.

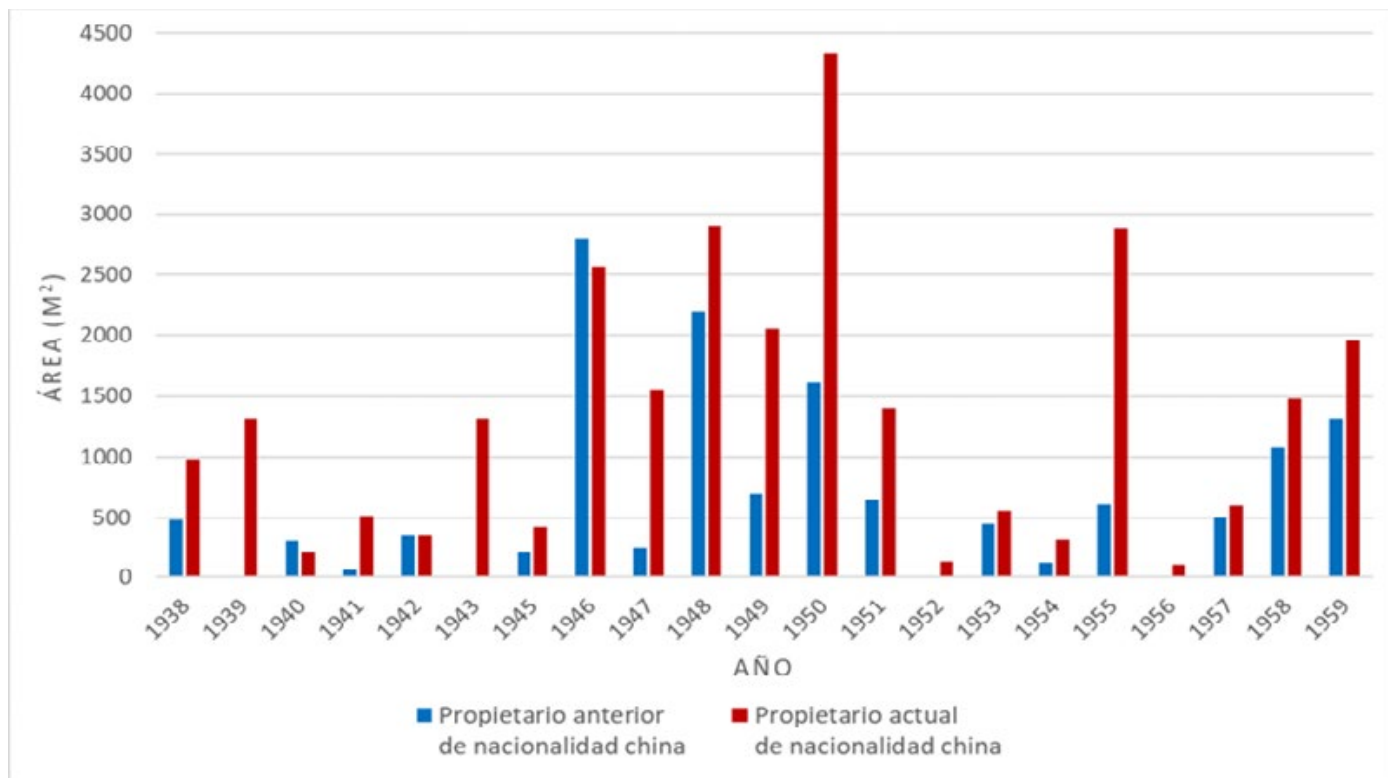

Elaboración propia

En este proceso, también podemos destacar y visualizar a los 20 chinos que acaparan la mayor cantidad de transacciones (Tabla 4), destacando Arturo Chau Ly, con 13 propiedades. En menor proporción le siguen Carlos Chiang Ly, Federico Loo Cam y Gregorio Yap. 


\section{Tabla 4}

Ranking de los ciudadanos chinos que más transacciones de compraventa realizaron entre 1938 y 1959. Fuente: Archivo Gobernación de Tocopilla, Registro de propiedades del Ministerio de Bienes Nacionales para la ciudad de Tocopilla.

\begin{tabular}{|c|c|}
\hline Nombre & $\begin{array}{c}\mathrm{N}^{\circ} \text { de Transacciones de } \\
\text { compraventa }\end{array}$ \\
\hline Arturo Chau Ly & 13 \\
\hline Carlos Chiang Ly & 4 \\
\hline Federico Loo Cam & 4 \\
\hline Gregorio Yap & 3 \\
\hline Manuel F., Sueylian Lilian y Mario Mak & 3 \\
\hline Ramon Young Wong & 3 \\
\hline Alfredo Cam Ku & 2 \\
\hline Guillermo Chang & 2 \\
\hline Guillermo Loo Cam & 2 \\
\hline Hilario Chan Lin & 2 \\
\hline Li Gin Yen & 2 \\
\hline Misan, Eloisa y Exequiela Chang & 2 \\
\hline Misan, Mercedes, Miguel y Exequiela Chang & 2 \\
\hline Oscar Lin Chiang & 2 \\
\hline Roberto Hafon Yon & 2 \\
\hline Rosa Vera Vda. de Chumez, Lidia y Juana Chumez & 2 \\
\hline Samuel Chumey S. & 2 \\
\hline Santiago Chau Ly & 2 \\
\hline Santiago Chiong Chan & 2 \\
\hline Sociedad Comercial Chiang y Cía. Ltda. & 2 \\
\hline
\end{tabular}

Elaboración propia 
Del mismo modo, podemos analizar los 9 primeros lugares de chinos que agencian una mayor cantidad de transacciones y , sumando los metros cuadrados, encontramos que nuevamente Arturo Chau Ly acumula la mayor cantidad (Tabla 5 y Gráfico 4). El tercer lugar está ocupado por la mujer que fue casada con el hijo de Arturo Chau Ly, Ilamado Hilario Chau, quien falleció en un accidente aéreo el 26 de marzo de $1955^{81}$.

\section{Tabla 5}

Ranking de los migrantes chinos que más metros cuadrados gestionaron entre 1938 y 1959. Fuente: Archivo Gobernación de Tocopilla, Registro de propiedades del Ministerio de Bienes Nacionales para la ciudad de Tocopilla.

\begin{tabular}{ll}
\hline \multicolumn{1}{c}{ Nombre } & Total de m2 \\
\hline 1. Arturo Chau Ly & 4546,2 \\
\hline 2. Federico Loo Cam & 2980,8 \\
\hline 3. O. Riffo de Chau, Yammy, Rosa y C. Chau & 2395,9 \\
\hline 4. Gregorio Yap & 1153,6 \\
\hline 5. Juan Chang Man & 1000,0 \\
\hline 6. Guillermo Chang & 878,8 \\
\hline 7. Sociedad Comercial Chiang y Cía. Ltda. & 830,0 \\
\hline 8. Ramón Young Wong & 779,8 \\
\hline 9. Oscar Lin Chiang & 754,4 \\
\hline
\end{tabular}

Elaboración propia

81 La Prensa (Tocopilla) 6 de mayo de 2003. 


\section{Gráfico 4}

Identificación de los 9 migrantes chinos con la mayor cantidad de transacciones que realizaron y con la mayor cantidad de metros cuadrados que gestionaron durante 1938 y 1959 dentro de la colectividad. Fuente: Archivo Gobernación de Tocopilla, Registro de propiedades del Ministerio de Bienes Nacionales para la ciudad de Tocopilla.

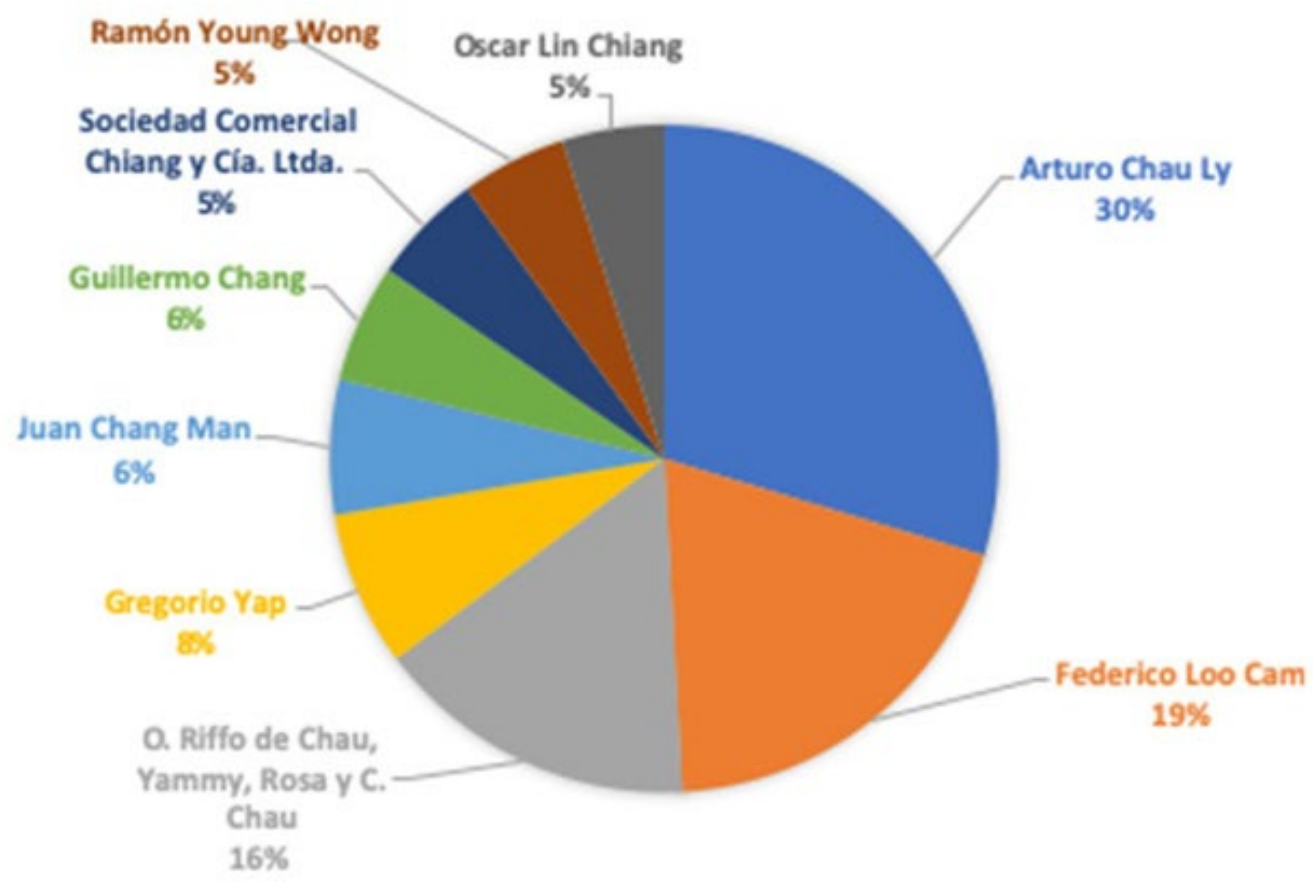

Elaboración propia

Si bien los chinos en los finales del siglo XIX y principios del siglo siguiente estaban ubicados en las periferias urbanas de Tocopilla, estos datos de transacción nos dan las luces no solo de un proceso de participación socioeconómica, sino que también de una movilidad espacial: gran parte de los chinos agencian sus actividades en la calle principal de la ciudad, la calle 21 de Mayo, arteria que aglutina al $31 \%$ del total de metros cuadrados, lo que equivale a 10.610,4 m2, gestionados con 34 transacciones, equivalente al $34 \%$ del total de las transacciones.

La segunda calle que aglutina a chinos, es una calle paralela a 21 Mayo, la calle Sucre, con el $12,7 \%$ del total de metros cuadrados, gestionados con 15 transacciones, que corresponde al $12,4 \%$.

Una calle paralela a Sucre, hacia el oriente, es la calle Guillermo Matta, la cual ocupa el tercer lugar con un total de 2207,9 m2. En ese sentido, la tabla 6 nos ofrece el ranking o la jerarquización de las calles que aglutinaron la mayor cantidad de transacciones, y nos ofrece también una mirada a las calles donde más metros cuadrados se transaron. 


\section{Tabla 6}

Ranking de calles de Tocopilla donde se evidencia la mayor cantidad de transacciones y las áreas en metros cuadrados involucrados. Fuente: Archivo Gobernación de Tocopilla, Registro de propiedades del Ministerio de Bienes Nacionales para la ciudad de Tocopilla.

\begin{tabular}{|c|c|c|c|c|}
\hline \multirow{2}{*}{ Ranking de calles } & \multicolumn{2}{|c|}{ Transacciones } & \multicolumn{2}{|c|}{ Área $(\mathrm{m} 2)$} \\
\hline & $\mathrm{N}^{\circ}$ & $\%$ & Total & $\%$ \\
\hline 1. Calle 21 de Mayo & 34 & 28,1 & 10610,4 & 31,0 \\
\hline 2. Calle Sucre & 15 & 12,4 & 4346,8 & 12,7 \\
\hline 3. Calle Guillermo Matta & 14 & 11,6 & 2207,9 & 6,5 \\
\hline 4. Calle Aníbal Pinto & 11 & 9,1 & 2327,3 & 6,8 \\
\hline 5. Calle Washington & 7 & 5,8 & 797,5 & 2,3 \\
\hline 6. Calle Freire & 6 & 5,0 & 1860,0 & 5,4 \\
\hline 7. Calle Baquedano & 4 & 3,3 & 1675,7 & 4,9 \\
\hline 8. Calle Colón & 4 & 3,3 & 1122,1 & 3,3 \\
\hline 9. Calle O'Higgins & 4 & 3,3 & 1317,5 & 3,9 \\
\hline 10. Manzana N¹05 & 3 & 2,5 & 2246,0 & 6,6 \\
\hline 11. Calle Arturo Prat & 2 & 1,7 & 740,3 & 2,2 \\
\hline 12. Calle Barros Arana & 2 & 1,7 & 240,0 & 0,7 \\
\hline 13. Calle Bolívar & 2 & 1,7 & 2955,9 & 8,6 \\
\hline 14. Calle Latorre & 2 & 1,7 & 400,0 & 1,2 \\
\hline 15. Pasaje Matta & 2 & 1,7 & 164,0 & 0,5 \\
\hline 16. Calle Segunda Sur & 2 & 1,7 & 522,0 & 1,5 \\
\hline 17. Calle Serrano & 2 & 1,7 & 262,4 & 0,8 \\
\hline 18. Avenida Diagonal & 1 & 0,8 & 0,0 & 0,0 \\
\hline 19. Calle Población Pampa Este & 1 & 0,8 & 111,0 & 0,3 \\
\hline 20. Calle San Martín & 1 & 0,8 & 0,0 & 0,0 \\
\hline 21. Manzana 100 & 1 & 0,8 & 305,0 & 0,9 \\
\hline 22. Sin Información & 1 & 0,8 & 0,0 & 0,0 \\
\hline Total & 121 & 100,0 & 34211,7 & 100,0 \\
\hline
\end{tabular}


Estos procesos de centralización y de elitización de los chinos es un proceso opuesto a los rezagos y pauperización económica y material que se atestiguan en los bordes urbanos de Tocopilla. El diario La Prensa comentaba en julio de 1947 sobre la cara infausta del puerto que, "detrás de sus imponentes decorados, la ciudad oculta bastidores de pobreza y desesperación"82. Porque en los andurriales cercanos al cerro "existe una verdadera escuela del delito (...) de bandoleros de cualquier especie, la chiquillada se bate a cuadrillazo limpio (...) la realidad desnuda del arrabal. Una bocanada fétida nos ahoga, aparece el conjunto de miseria y desesperación" ${ }^{83}$. El matutino indica que los bordes urbanos son la escena de las calaminas y maderas viejas, trozos de saco que

se sostienen por milagros, que constituyen lo único que pretende dar forma a viviendas de gente humilde, de los desheredados de la suerte. Grandes y chicos se debaten en medio de una miseria que espanta, donde las enfermedades se enseñorean disputando las presas al hambre y la mugre ${ }^{84}$.

\section{Figura 6}

Plano de Tocopilla de 1940 que indica el proceso de movilidad socioespacial de los migrantes chinos. Puede advertirse los sectores periféricos donde habitaron $y$ trabajaron los chinos en los finales del siglo XIX y principios del XX. Del mismo modo, puede advertirse las tres principales calles donde la colectividad desarrolló mayores transacciones inmobiliarias, destacando la calle principal de la localidad, calle 21 de mayo, arteria donde se ubica la Plaza principal, los centros de poder y el propio Centro Chung Hwa. Archivo: Plano de la Dirección General de Tierras y Colonización, Departamento de Bienes Nacionales, 1940.

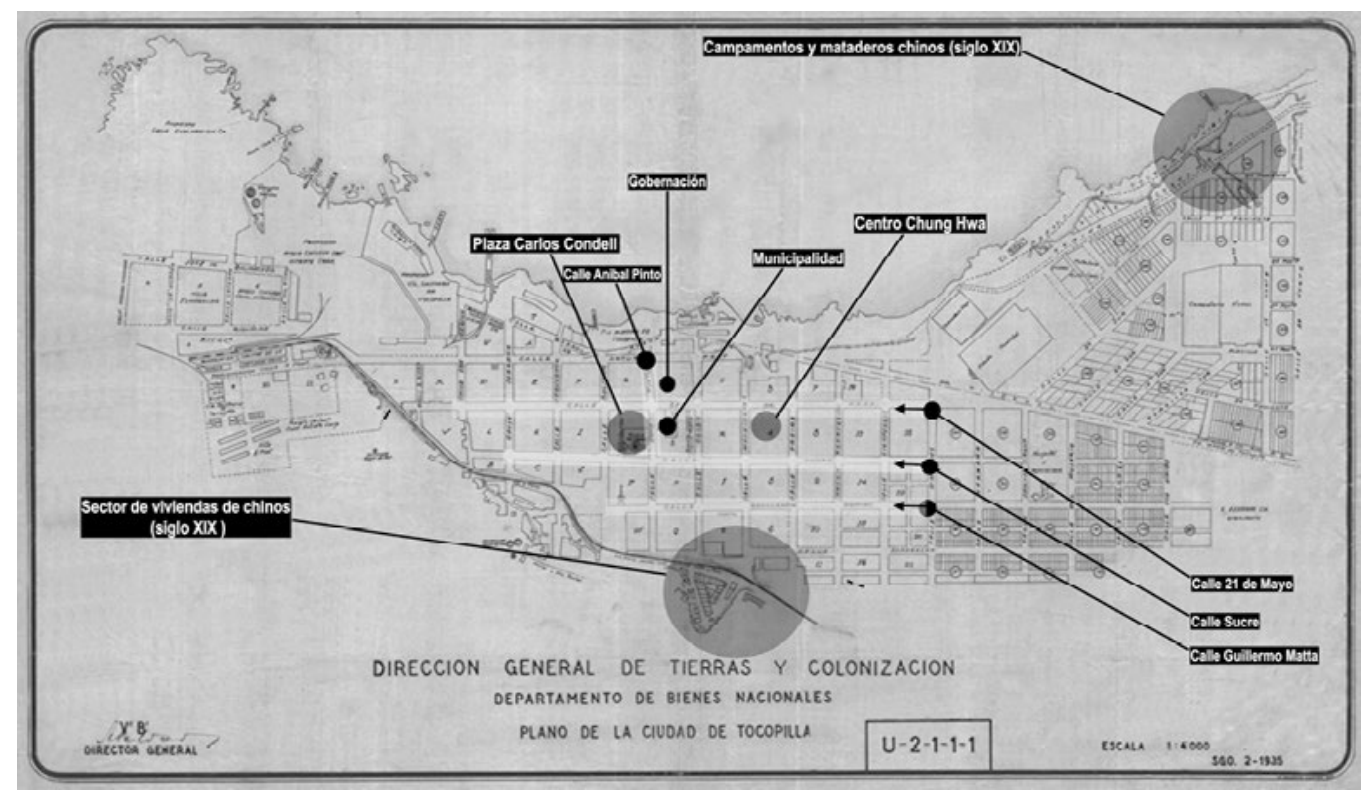

Esquematización e intervención propia.

82 La Prensa (Tocopilla) 13 de julio de 1947.

83 La Prensa (Tocopilla) 13 de julio de 1947.

84 La Prensa (Tocopilla) 13 de julio de 1947. 
El gráfico 5 nos permite analizar el caso particular de la calle 21 de Mayo, calle que aglutina a la elite local, además de la plaza principal, el comercio, los bomberos, municipalidad, gobernación y el propio Centro Chung Hwa. En ese gráfico es posible ver que las mayores transiciones y metros cuadrados asociados ocurren en 1950. Es decir, es posible ver la correlación que indica que a la mayor cantidad de transacciones en 1950 está correspondida con la mayor cantidad de metros cuadrados.

\section{Gráfico 5}

Cantidad de transacciones y metros cuadrados transados en la calle principal de Tocopilla, Calle 21 de Mayo, entre los años 1938 y 1959. Fuente: Archivo Gobernación de Tocopilla, Registro de propiedades del Ministerio de Bienes Nacionales para la ciudad de Tocopilla.

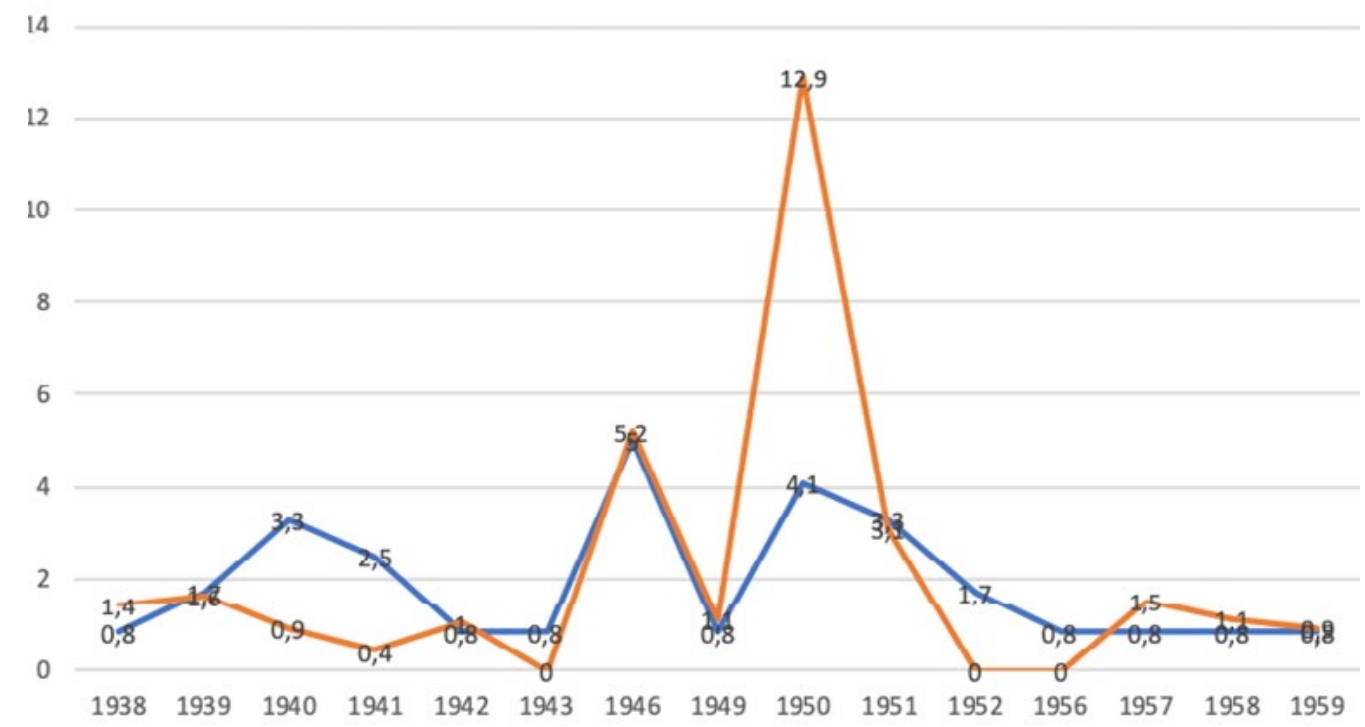

Elaboración propia 


\section{Comentarios finales}

En primer término, en este trabajo pudimos demostrar que la migración china en Tocopilla estuvo inscrita en procesos socioeconómicos que resultaron heterogéneos en sus modos de relación social, donde operaron discursos e imágenes que fueron híbridas, contradictorias y también, en varios casos, ofensivas y otras que resultaron halagüeñas. Así, se evidenció una migración conectada a territorios periféricos, con la asimilación de prácticas consideradas como delictivas y propias de la marginalidad, con chinos que se mantuvieron en una escena de rezago socioeconómico y de subalternidad, situación que estimuló instancias de discriminación y segregación ${ }^{85}$. A su vez, en ese mismo devenir simultáneo de la primera mitad del siglo XX, vemos a otros chinos en procesos de elitización. Esto último, con chinos activos en la vida social de una ciudad, con huaqiaos donantes y propietarios, y también como habitantes de las calles principales de una ciudad dinamizada por la exportación del salitre del sistema Guggenheim y que poseía también la termoeléctrica para la mina de Chuquicamata, circunstancias económicas propicias para establecer los diversos set de relaciones.

En ambos casos, está la identidad de los chinos como agentes del comercio, principalmente las tiendas y las ventas de carnes. En este último caso, vimos que en algunas épocas los chinos venden las carnes de más baja calidad. A su vez, se constatan otros chinos que venden carnes de primera categoría. Entonces, su presencia en la costa del desierto de Atacama estuvo cruzada por múltiples imágenes, realidades y tensiones que, de una u otra forma, dejaron una importante huella que nos habla de la densa transformación interna de un colectivo que se resistió a toda conformación sustancialista y homogénea.

Si bien los chinos fueron visibilizados en el marco del hostigamiento y criminalización, también acentuaron su presencia en el desierto con la existencia de "grandes hombres", muchos de ellos donantes, gracias a sus recursos excedentarios. De ese modo, aquellos sujetos de mecánicas agonísticas fueron construyendo una cara comunitaria, obteniendo así una legitimidad local, con un fuerte potencial simbólico y político que brindó el soporte de una posición de reputación beneficiosa. La donación construyó deudas que, de una o otra manera, fueron retribuidas a través del prestigio y la configuración de redes sociales que auxiliaron la reproducción de la elitización.

De esa manera, en la sociedad mercantil del desierto minero, la misma que remite a una verdadera periferia Estatal, los migrantes fueron valorizados según su potencia económica y donativa. Una fetichización y métrica de prestigio que se definía según lo donado. Allí, a contrariu sensu, se evidencia la aporofobia que cargó el chino que no pudo conectar con aquellas dinámicas por efecto de no contar con una potencia agonística ni con la posibilidad de quemar los excedentes. Suficiente semántica de la sociología del desierto para excluirlo y discriminarlo por no participar en las dinámicas de intercambio.

85 Sobre otros procesos de discriminación y violencia hacia migrantes chinos, especialmente a coolies vinculados a la extracción del guano en la zona de Tocopilla, ver Galaz-Mandakovic, D. (2019). 
Fue allí cuando el dinero fetichizado funcionando como capital que activa relaciones, devino "como valor dotado del poder de engendrar por sí mismo el valor, como dinero capaz de engendrar dinero" (Godelier, 1996, p.97). En otras palabras, la lógica agonística presente en las relaciones del mundo chino ensambló por diferentes vías en la lógica de la generación del capital legitimada en la sociedad capitalista del norte de Chile. Al parecer la maquinaria de la generación y acumulación del capital, la transformación permanente de mercancía y de dinero en capital y a la inversa, encontró un punto de encuentro y analogías con el potlach chino. El intercambio mercantil y el contrato, por una parte, y lo no-contractual ni "negociable", la reciprocidad, por otra, parecen haber ensamblado como aspectos relevantes que sostuvieron la vida social del mundo chino en Chile.

\section{Referencias bibliográficas}

Anspach, M. (2004). Violence et don. La preuve par Troie. Revue du MAUSS 23, 57-62.

Archivo Biblioteca Congreso Nacional de Chile. (1906, 15 de noviembre). Cámara del Senado, sesión 13a extraordinaria.

Archivo Gobernación Provincial de Tocopilla. (1927, 26 de abril). Oficio № 16, Comisaría de Tocopilla al Sr. Gobernador: dá cuenta de fumadero de opio y pide aplicación de "Ley de Residencia".

Archivo Gobernación Provincial de Tocopilla. (1939, 22 de julio). Decreto №12, Comisariato Departamental de Subsistencia y Precios.

Archivo Gobernación de Tocopilla. (1939, 11 de octubre). Policía de Investigaciones, Comunicación de novedades № 230 .

Archivo Gobernación Provincial de Tocopilla. (1939, 5 de diciembre). Decreto №144, Subdelegación de El Toco, María Elena.

Archivo Gobernación Provincial de Tocopilla. (1941, 6 de noviembre). Oficio №342, Al Sr. Gobernador. Remite: Subdelegación Civil de Toco, Oficina María Elena.

Archivo Gobernación Provincial de Tocopilla. (1942, 13 de diciembre). Oficio №24, Al Sr. Comisario de Carabineros de Tocopilla. Remite: Gobernador.

Archivo Gobernación de Tocopilla. (1943, 21 de enero). Copia de Oficio municipal №94.

Archivo Gobernación Provincial de Tocopilla. (1943, 31 de marzo). Oficio №247, Al Sr. Presidente Chung Hwa. Remite: Gobernador Márquez. 
Archivo Gobernación Provincia de Tocopilla. (1943, 1 de diciembre). Oficio №741, Al Sr. Presidente Centro Chung Hwa.

Archivo Gobernación Provincia de Tocopilla. (1944, 12 de enero). Oficio №89, A/ Sr. Presidente Centro Chung Hwa.

Archivo Gobernación de Tocopilla. (1944, 3 de marzo). Acta de sesión de la Sociedad de Comerciantes Minoristas.

Archivo Gobernación Provincial de Tocopilla. (1944, 10 de marzo). Oficio №23, Dirección General de Investigaciones, Al Sr. Gobernador.

Archivo Gobernación Provincial de Tocopilla. (1944, 5 de mayo). Doc. №81, Sobre producción de cueros. Al Sr. Comisario general de Subsistencia y Precios.

Archivo Gobernación Provincial de Tocopilla. (1944, 5 de junio). Doc. №95, Sobre producción de cueros. Al Sr. Comisario general de Subsistencia y Precios.

Archivo Gobernación de Tocopilla. (1946, 25 de junio). Policía de Investigaciones, Comunicación de novedades № 144.

Archivo Gobernación Provincial de Tocopilla. (1954, 15 de septiembre). Oficio confidencial №21, Dirección General de Investigaciones, Al Sr. Gobernador.

Archivo Provincial de Tocopilla. (1912, 17 de agosto). Oficio № 12, Al Sr. Gobernador, remite: Juan Carlos Bischofshofen, prefectura de policía.

Archivo Provincial de Tocopilla. (1921, 1 de octubre). Oficio s/n, A/ Sr. Gobernador Departamental, Remite: Comisario Jorge Bonilla.

Archivo Provincial de Tocopilla. (1923, 27 de mayo). Oficio №34, Al Sr. Gobernador, remite Alcalde E. Mascayano.

Archivo Provincial de Tocopilla. (1924, 7 de febrero). Carta s/n Al Sr. Gobernador: solicitud para uso de arma.

Archivo Provincial de Tocopilla. (1929, 9 de marzo). Oficio № 99, Al Prefecto de Policía de Tocopilla, remite Gobernador Fuenzalida, autorización uso de armas.

Archivo Provincial de Tocopilla (1931, 19 de marzo). Oficio №23, Al Sr. Intendente de Antofagasta, petición de restricciones a la inmigración china, firma alcalde $L$. Cárcamo.

Archivo Provincial de Tocopilla. (1932, 12 de junio). Carta s/n Al Sr. Gobernador. Remite: J. Chang. 
Archivo Provincial de Tocopilla. (1932, 15 de julio). Carta s/n A/ Sr. A/calde Rencoret Remite: J. Chang.

Archivo Provincial de Tocopilla. (1932, 12 de agosto). Oficio №17, Al Sr. Chang. Respuesta de Gobernador Peralta.

Archivo Provincial de Tocopilla. (1938, 22 de julio). Oficio №110, Al Sr. Gobernador. Remite: J. Lafourcade Mendoza, Mayor de Carabineros.

Bao Rong (2013). Capítulo II: 1893-1949. En Sociedad de Beneficencia de Colonia China en Chile-Asia Reps (Eds.), Breve Historia. Sociedad de Beneficencia de la Colonia China en Chile a sus 120 años (1893-2013), pp.39-55. Santiago de Chile, s/e.

Beltrán, J. (2003). Los ocho inmortales cruzan el mar. Bellaterra.

Banco Interamericano de Desarrollo. (2004). Cuando Oriente llegó a América: contribuciones de inmigrantes chinos, japoneses y coreanos. BID.

Campdelacreu, E. (2009[1949]). Tocopilla: una memoria de prueba. Agrupación Cultural y Folclórica Tikopillan.

Chou, D.L. (2004). Chile y China: inmigración y relaciones bilaterales (1845-1970). Centro de Investigaciones Diego Barros Arana (Dibam).

Collao, J. (2001 [1970]). Historia de Tocopilla. Ediciones Frontera. Corporación Juan Collao Cerda.

Earley, C. (1997). Face, harmony, and social structure: An analysis of organizational behavior across cultures. Oxford University Press.

El Abecé (1921, 7 de diciembre).

El Industrial (Antofagasta) (1884, 29 de noviembre).

El Industrial (1906, 6 de enero).

El Industrial (Antofagasta) (1906, 16 de agosto).

El Industrial (Antofagasta) (1906, 26 de octubre).

Henríquez Vásquez, R. (2004). La jarana del desierto: burdeles, prostitutas y pampinos en Tarapacá, 1890-1910. En Colectivo Oficios Varios (Editor), Arriba quemando el sol. Estudios de Historia Social Chilena: Experiencias populares de trabajo, revuelta y autonomía (1830-1940) pp. 111-136. LOM.

Flahaut, F. (2004). Identité et reconnaissance dans les contes. Revue du MAUSS, 23, 31-56. 
Galaz-Mandakovic, D. (2013). Migración y biopolítica. Dos escenas del siglo XX tocopillano. Retruécanos Ediciones.

Galaz-Mandakovic, D. (2019). Movimientos, tensiones y luces. Historias tocopillanas. Ediciones Bahía Algodonales.

Godelier, M. (1996). L'enigme du don. Libraire Fayar/Flammarion.

Goffman, E. (1955). On Face-Work: An Analysis of Ritual Elements in Social Interaction. Psychiatry: Journal of Interpersonal Relations, 18, 213-231.

Greenhalg, S. (1994) De-Orientalizing the Chinese Family Firm. American Ethnologist, 21(4), 742-771.

Greenhalg, S. (2010). Cultivating Global Citizens: Population in the Rise of China. The Edwin O. Reischauer Lectures 2008. Harvard University Press.

Ho, D. (1976). On the Concept of Face. The American Journal of Sociology, 81, 867-884.

Hwang, K. (1987). Face and Favor: The Chinese Power Game. The American Journal of Sociology, 92, 944-974.

Kalazich, F. (2018). Para estudiar la prostitución en las pampas salitreras. Apuntes desde los estudios subalternos y la arqueología industrial. Revista Chilena Antropología, 37, 131-142. https://doi.org/10.5354/0719-1472.2018.49487

La Cachimba (Antofagasta) (1930, 31 de mayo).

La Nación (1917, 15 de enero).

La Nación (Santiago) (1927, 11 de octubre).

La Nación (Santiago) (1929, 9 de octubre).

La Nación (Santiago) (1933, 12 de agosto).

La Nación (1938, 21 de marzo).

La Prensa (Tocopilla) (1929, 7 de agosto).

La Prensa (Tocopilla) (1935, 7 de enero).

La Prensa (Tocopilla) (1944, 25 de diciembre).

La Prensa (Tocopilla) (1947, 13 de julio).

La Prensa (Tocopilla) (2003, 6 de mayo). 
Ley $N^{\circ} 3.446$ (1918, 12 de diciembre). Lei Núm 3,446 que impide la entrada al país o la residencia en él de elementos indeseables. Ministerio del Interior. Archivo Biblioteca del Congreso Nacional de Chile. https://www.bcn.cl/leychile/ navegar?idNorma=23974

Mauss, M. (2008). Essai sur le don. Forme et raison de l'échange dans les sociétés archaïques. En Sociologie et anthropologie pp. 145-284. PUF.

Moraga, J. (2012). Las nuevas "caras” (mianzi, 面子) en los chinos de España: reciprocidad y mercado. Revista de Antropología Social RAS, 21, 217-250. https://doi.org/10.5209/rev_RASO.2012.v21.40057

Nieto, G. (2007) La inmigración china en España. Una comunidad ligada a su nación. Catarata/UAM.

Palma, P. y Montt M. (2017). La diáspora china en lquique y su rol en la política de ultramar durante la República y el inicio de la Guerra Fría (1911-1950). Diálogo Andino, 54, 143-152.

Sahlins, M. (1963). Poor Man, Rich Man, Big-Man, Chief: Political Types in Melanesia and Polynesia. Comparative Studies in Society and History, 5(3), 285-303.

Sahlins, M. (2010). La sociedad contra el estado. Ed.Virus.

Salazar, G. (1985). Labradores, peones y proletarios. Ediciones Sur.

Semanario 4 de Junio (Tocopilla) (1939, 4 de junio).

Semanario La Cosa (1954, junio).

Stuven, A. M. y Fermandois, J. (2011). Historia de las mujeres en Chile. Taurus.

Wang Minghui (2011). The virtues of Overseas Chinese: Exhibits in the Guangdong Overseas Chinese Museum. World Affair Press.

Yan, Y. (1996). The Flow of Gifts: Reciprocity and Social Networks in a Chinese Village. Stanford University Press. 


\section{Archivos}

Archivo Biblioteca Congreso Nacional de Chile.

Archivo Gobernación Provincial de Tocopilla.

Archivo fotográfico de Moy-San Tan.

Archivo fotográfico de Yuksin Cam Loo.

\section{Diarios}

Diario El Abecé (Antofagasta).

Diario El Industrial (Antofagasta).

Diario La Nación (Santiago).

Diario La Prensa (Tocopilla).

Semanario La Cachimba (Antofagasta).

Semanario La Cosa (Tocopilla).

Semanario 4 de junio (Tocopilla). 